\title{
LOGROS, ERRORES Y RESPONSABILIDADES PARA EL FUTURO DE LA PSICOLOGÍA HUMANISTA
}

\section{ACHIEVEMENTS, MISTAKES, AND RESPONSIBILITIES FOR THE FUTURE OF HUMANISTIC PSYCHOLOGY}

\author{
Ramón Rosal Cortés
}

Instituto Erich Fromm de Psicoterapia Integradora Humanista, Barcelona, España

Cómo referenciar este artículo/How to reference this article:

Rosal Cortés, R. (2017). Logros, errores y responsabilidades para el futuro de la Psicología Humanista. Revista de Psicoterapia, 28(107), 85-126.

\begin{abstract}
Resumen
Se presenta aqui el texto que se ofreció como ponencia en el I Congreso Internacional de Psicología y Psicoterapias Humanistas que tuvo lugar, en noviembre de 2015, en Barcelona. El artículo se ocupa de responder a tres cuestiones principales: $1^{a}$ Desde que se inició públicamente el Movimiento de la Psicología Humanista, en 1961, al crearse la American Association for Humanistic Psychology y el Journal of Humanistic Psychology, ¿cuáles podemos considerar sus principales logros hasta la actualidad? ¿Qué influencias beneficiosas ha producido en el colectivo de los psicólogos, psicoterapeutas y otros profesionales de la salud?; $2^{a}$ Dentro del pluralismo de modelos terapéuticos relacionados, en algún grado, con la Psicología Humanista, ¿qué principales errores -o, al menos, deficiencias- se pueden señalar en una parte de sus profesionales? ¿Qué infidelidades respecto a las aspiraciones originales del Movimiento? ¿Se ha logrado superar plenamente lo que Rollo May (1986, p. 33) calificó como "período de infancia y de adolescencia" de la Psicología Humanista? $3^{a}$ Finalmente, ¿qué nuevas posibilidades se ofrecen a los implicados en las psicoterapias existencial-humanistas, teniendo presentes algunos de los principales problemas actuales experimentados por individuos y sociedades? ¿Serán capaces los psicólogos humanistas de influir beneficiosamente no sólo respecto a los primeros, sino también respecto a las segundas? El objetivo era seleccionar-sobrepasado el medio siglo de historia del Movimiento de la Psicología Humanista- un conjunto de materiales idóneos para futuros trabajos sobre historia de las psicoterapias humanistas.

Palabras clave: Psicología Humanista, logros de la Psicología Humanista, errores de la Psicología Humanista, responsabilidades de la Psicología Humanista, Historia.
\end{abstract}

Fecha de recepción: 13 de mayo de 2017. Fecha de aceptación: 15 de junio de 2017.

Correspondencia sobre este artículo:

E-mail: ramonrosalc@gmail.com

Dirección postal: c. Madrazo 113, enlo. 2ª 08021 Barcelona, España

(C) 2017 Revista de Psicoterapia 


\section{Abstract}

Presented here is the text that was offered as a presentation at the First International Congress of Psychology and Humanistic Psychotherapies which took place in November of 2015, in Barcelona. The article is occupied to answer three main questions: 1 st since the movement of humanistic psychology was publicly launched in 1961, at the American Association for Humanistic Psychology and the Journal of Humanistic Psychology created, What can be considered its main achievements until now? What beneficial influences has it produced in psychologists, psychotherapists and other health professionals? 2nd Within pluralism related therapeutic models, to some degree, with humanistic psychology, what major mistakes, or at least-noted deficiencies, can be seen in its professionals? What infidelities from the original aspirations of the Movement? Has it been able to fully overcome what Rollo May (1986, p. 33) called "childhood and adolescence" of Humanistic Psychology"; 3rd Finally, thinking about the future, what new opportunities are offered to those involved in the existential-humanistic psychotherapies, bearing in mind some of the main problems experienced by individuals and societies? Will humanistic psychologists be able to beneficially influence not only with the first, but also with regard to the latter?

Keywords: Humanistic Psychology, achievements of Humanistic Psychology, mistakes of Humanistic Psychology, responsabilities of Humanistic Psychology, History. 
Se presenta aquí el texto que se ofreció - en forma abreviada-como ponencia en el I Congreso Internacional de Psicología y Psicoterapias Humanistas que tuvo lugar, durante el mes de noviembre de 2015, en Barcelona, en la Universitat Ramon Llull. El objetivo era seleccionar -sobrepasado el medio siglo de historia del Movimiento de la Psicología Humanista- un conjunto de materiales idóneos para futuros trabajos sobre historia de las psicoterapias humanistas. Materiales que respondiesen a tres cuestiones: a) cuáles pueden considerarse logros innovadores de las psicoterapias humanistas que, a su vez, han sido reconocidos e integrados como válidos -al menos en parte-fuera del ámbito del Movimiento de la Psicología Humanista; b) cuáles pueden señalarse como errores principales que se han cometido por una parte de los psicoterapeutas vinculados a modelos humanistas; c) qué responsabilidades sería conveniente que los terapeutas que trabajan en diversos modelos existencial-humanistas asumiesen cara al futuro. Pero antes de responder a estas tres cuestiones es conveniente señalar en qué autores se está pensando -por parte del autor de este trabajo- cuando se utiliza el término - más bien ambiguo de "psicólogo o psicoterapeuta existencial-humanista".

Ha pasado más de medio siglo desde que un conjunto de psicólogos y psiquiatras norteamericanos y europeos residentes en los Estados Unidos decidieron reunirse al haber comprobado, a través de sus escritos, y sus intervenciones en congresos, que coincidían en unas mismas inquietudes. Además de psicólogos y psiquiatras vinculados a diferentes paradigmas y escuelas psicológicas- había otros diversos profesionales de la relación de ayuda. Había también profesores e investigadores sobre otras ciencias humanas, y filósofos. A pesar de su diversidad de saberes, y de teorías psicológicas y psicoterapéuticas, compartían un sentimiento de malestar respecto al concepto de ser humano implicado en el paradigma conductista que tenía el poder en las universidades. También, respecto a algunas de las teorías del psicoanálisis ortodoxo, lo cual no les impedía valorar y agradecer de Freud que fuese uno de los primeros médicos que se tomó en serio el psiquismo humano.

El teórico de la personalidad Henry Murray nos dejó un resumen de esta inquietud en el párrafo siguiente, en el que describe el concepto de ser humano que ofrecían los psicólogos:

El hombre es una computadora, un animal, o un niño. Su destino está completamente determinado por genes, instintos, accidentes, condicionamientos y reforzamientos tempranos, fuerzas culturales y sociales $[\ldots]$ no se prevé nada para la creatividad, no se admiten márgenes de libertad para las decisiones voluntarias, ni hay ningún reconocimiento atinado del poder de los ideales, ninguna base para acciones desinteresadas (Murray, cit. en Bertalanffy, 1976, pp. 215s.).

Al mismo tiempo, Ludwig von Bertalanffy, biólogo y teórico de la Ciencia, creador de la Teoría General de los Sistemas, implicado también entre los que compartían la misma inquietud, manifestaba su esperanza y alegría al comprobar que representantes de escuelas neofreudianas (como Fromm y Horney), de la 
psicología del yo, de nuevas teorías de la personalidad como los humanistas Allport y Maslow, y de la psicología existencial, estaban dispuestos a mostrar la invalidez de lo que Bertalanffy llamaba la imagen del "hombre-robot", robot de los estímulos ambientales, o de impulsos psicofisiológicos.

Así surgió el movimiento social de la Psicología Humanista mientras Abraham Maslow y Antony Sutich fundaron el Journal of Humanistic Psychology en 1961, y al año siguiente la American Association for Humanistic Psychology que pronto, al pasar a internacional, suprime el término American.

Hay que advertir de que el término psicólogo humanista o, más exactamente, psicólogo existencial-humanista, aquí se vincula a tres grupos de personas:

1. Al colectivo de fundadores y primeros implicados en el Movimiento: Charlotte Bühler, James Bugental, Stephen Cohen, Sidney Jourard, Abraham Maslow, Rollo May, Clark Moustakas, Carl Rogers, S. Stanfelt Sargent y Frank T. Severin. Se desvincularon Kelly, May, Murphy y Murray, aunque May pronto se reintegró.

2. A los que fueron creadores de nuevos modelos de psicoterapia que fueron acogidos por el Movimiento, a través de sus Congresos y publicaciones, principalmente:

a) C. Rogers, creador de la Psicoterapia Centrada en la Persona

b) E. Berne, creador del Análisis Transaccional

c) F. Perls, creador de la Psicoterapia de la Gestalt

d) R. Assagioli, creador de la Psicosíntesis

e) E. Gendlin, creador del Focusing

f) A. Lowen, creador de la Bioenergética

g) D. Boadella, creador de la Biosíntesis

h) A. Mahrer, creador de la Psicoterapia Existencial

3. a todos aquellos psicólogos anteriores al surgimiento de la Psicología Humanista, o posteriores, que no se autodenominan necesariamente psicólogos o psicoterapeutas humanistas, pero -dentro de su diversidad- les une el hecho de compartir, entre otras características, principalmente una concepción:

- Holista y sistémica de la persona humana singular, frente a una visión atomista

- Que reconoce la capacidad de libertad, frente a una visión mecanicista y determinista de la persona

- Así como también reconoce la complejidad y unicidad de la misma, frente a toda visión reduccionista, de cualquier tipo

Entre ellos se encuentran:

a) Teóricos de la personalidad, motivaciones, emociones, etc., como William James, Gordon Allport, Henry Murray, Philip Lersch, Hans Thomae, G.Stanley Hall, Kurt Goldstein y Edwar Spranger

b) Excolaboradores de Freud, como Otto Rank, Alfred Adler y Carl G. Jung.

c) Neopsicoanalistas, como Erich Fromm, Karen Horney y J.L. Moreno 


\section{Logros}

\section{$1^{\circ}$ Concepción holista y sistémica de la personalidad}

Un primer logro a destacar es el claro predominio de las concepciones holista y sistémica de la personalidad frente a las atomistas y reduccionistas.

Los teóricos de la Psicología Humanista manifestaron un interés acentuado por el estudio de la personalidad en su conjunto, singularidad e historicidad. La personalidad de un individuo no es entendida como la suma o yuxtaposición de funciones o procesos (cognitivos, emocionales, conductuales), sino como un sistema o conjunto organizado de forma peculiar en cada sujeto, un sistema configurado y en proceso de desarrollo. Los sistemas -o mejor subsistemaspsicofísicos que integran la organización o sistema de la personalidad están interrelacionados, pudiéndose producir una influencia recíproca entre ellos.

Cabe trabajar, con finalidad de cambio psicoterapéutico, a partir predominantemente de intervenciones emocionales, cognitivas, imaginarias, o corporales Psicoterapia de la Gestalt Gimeno-Bayón, 2012a), Análisis Transaccional en su escuela clásica (Gimeno-Bayón, 2012b; Gimeno-Bayón y Rosal, 2012), terapias psicocorporales como la Bioenergética entre otras). Sin embargo, en cualquiera de estos enfoques, para que el terapeuta sea fiel a un enfoque humanista no perderá de vista que estas diferentes vías pretenden dar lugar a un cambio en la organización del conjunto de la personalidad y sus diferentes subsistemas.

Asimismo tenderá a no perder de vista el carácter singular e irrepetible de todo sujeto humano. El interés de la P.H. por esta actitud tiene probablemente su primer representante destacado en Allport (1975). Para este autor la unicidad constituye el mayor dilema para el psicólogo clínico que, si pretende interpretar la conducta del paciente con algunas hipótesis de un modelo terapéutico determinado, constata las dificultades de acoplarse plenamente al mismo.

La individualidad es una característica primaria de la naturaleza humana. Para el desarrollo de la ciencia de la personalidad debemos aceptar este hecho. Pero es más fácil construir un hombre artificial a partir de normas universales y de grupo que estudiar adecuada y científicamente un ser real (Allport, 1975 p.39).

Para Allport -y podemos considerar que, al menos de forma implícita, para el conjunto de la P.H.-es claramente simplificadora la visión científica nomotética del individuo, en especial si se acepta la definición que Eysench ofreció: "Para el científico, el individuo es, simplemente, el punto de intersección de un cierto número de variables cuantitativas" (Eysench, 1952, p. 18).

Significa que el científico no se interesa por la mutua interdependencia de los sistemas parciales dentro del sistema entero de la personalidad. Se interesa solamente por dimensiones aisladas, que le permiten establecer comparaciones entre muchas personas [...] El científico no se interesa en el sistema de la personalidad como un todo, sino solamente en las dimensiones 
comunes. Deja a la persona como mero "punto de intersección", sin estructura interna, sin coherencia ni sentido (Allport, 1975, p. 25).

Por supuesto que actualmente, fuera del ámbito de la Psicología Humanista, el interés hacia el concepto de personalidad se ha difundido, distanciándose claramente de los dos paradigmas de los años cincuenta y sesenta del pasado siglo. Pero el papel de los psicólogos humanistas ha sido notable en estos procesos de cambio. Pinillos, el que probablemente fue el primer psicólogo científico español, así lo reconoció cuando escribió -con la libertad del jubilado- estos párrafos en 1987:

A cuenta de la llamada psicología humanística-tercera fuerza, otras veceshay que cargar el mérito de haber mantenido vivas, contra viento y marea, una serie de ideas que los reduccionismos de las distintas escuelas han excluido cuidadosamente de sus respectivos campos de investigación, sobre todo al ocuparse de la personalidad.

De formas muy variadas, porque el área cubierta por las psicología humanística tiene unos confines borrosos y un contenido heterogéneo, los representantes de esta opción han procurado que la psicología de la personalidad no pierda de vista la existencia de un núcleo de cualidades sui generis tales como la libertad, la dignidad y la conciencia de sí, privada de las cuales la noción misma de personalidad queda degradada. La idea de que, por modos muy diversos, en la personalidad humana refulge el valor incondicionado de la persona, es probablemente la clave del arco que cobija a todas las teorías humanísticas de la personalidad. [...]

En cuanto fuente de inspiración, como conciencia crítica de los convencionalismos, estrecheces y limitaciones de la psicología científica de la personalidad, esta opción humanística tiene asegurado un puesto permanente, un poco honorífico, ésa es la verdad, en la disciplina. No siempre es viable traducir a términos verificables los valores que todas estas corrientes pretenden defender en el estudio de la personalidad; pero constituiría una crasa equivocación no caer en la cuenta de que en la anteposición que hacen del objeto al método tiene, precisamente en el estudio de la personalidad, mayor sentido que en ninguna otra parcela de la psicología (Pinillos, 1987, pp. 14ss.).

\section{$2^{\circ}$ Investigación idiosincrásica}

Un segundo logro de la Psicología Humanista es el de haber investigado con un enfoque predominantemente idiosincrásico para la comprensión de la persona, de los sistemas en que está implicada, y de los subsistemas que la integran.

Predominio no significa exclusividad. May trató de compaginar-como vías complementarias - la visión idiosincrásica (que consideraba la principal) y la nomotética. Para May el ser humano se encuentra ante un dilema existencial que "emerge de la capacidad del hombre para vivir a la vez como sujeto y objeto. Ambas vivencias son necesarias, para la ciencia psicológica, para la terapia y para una vida 
placentera" (May, 1978, p. 21). Un error frecuente consiste, según él, en la actitud simplificadora por la que se trata de evitar el dilema negando uno de sus extremos. En psicoterapia este dilema se manifiesta en que puede percibirse al paciente desde dos puntos de vista: o como un organismo que, según los diagnósticos, se adecúa en mayor o menor grado a determinado modelo, o como un sujeto singular e irrepetible con el que se establece una relación interpersonal y con el que se ejercita una actitud de empatía que facilita comprender mejor el significado de su lenguaje verbal y no verbal.

Un colega psicoterapeuta señala que alterna como en un partido de tenis entre ver al paciente como un objeto, cuando piensa en modelos, dinámica, prueba de realidad y otros aspectos de los principios generales con los que se relaciona la conducta del paciente; y como un sujeto, cuanto siente empáticamente el sufrimiento del paciente y ve el mundo a través de su punto de vista (May, 1978, p. 23).

Esta complementariedad de actitudes o percepciones se requiere, según May, tanto en el terapeuta, como en el científico de la psicología, como en todo ser humano que quiera respetar en su vida cotidiana la complejidad de la realidad humana, sin negar ni su vertiente condicionada y manipulable, ni la zona de su libertad o creatividad. Según May, la libertad equivale a la capacidad de vivenciar de forma dialéctica ambas vertientes en uno mismo. Tiene presente la afirmación del físico Heisenberg cuando le subrayó que consideraba una ilusión la creencia en la posibilidad de observar la naturaleza como un objeto externo separado del sujeto y se lamentó de que en la Psicología se fomente esta actitud, cuando en esta ciencia, al tener que utilizar el investigador los mismos procesos cuyos mecanismos y estructuras trata de descifrar, la simplificación que se produce resulta incomparablemente más grave que en la física.

Notemos que May recalca la complementariedad de ambos enfoques como un requisito también en el trabajo científico, acercándose mucho su posición conciliadora a la de Rogers. Una vez más no aparece ningún menosprecio a la posible aportación científica objetivadora del psiquismo humano. Este autor se sitúa, según su propia declaración, dentro de la tradición del filósofo y psicólogo William James, en cuyo pensamiento se encuentran grandes afinidades con el enfoque existencial compaginadas con una actitud respetuosa de la objetividad científica. En James se había simultaneado la elaboración de la psicología descriptiva con la explicativa. James trató de preservar el carácter de complemento mutuo de ambos puntos de vista, cosa que sólo es posible sobre la base de una teoría del hombre en tanto fuente integral de la experiencia, de una teoría de un modo original de existir, de una fenomenología del mundo experienciado, fenomenología implícita en James (van Kaam cit. en May, Allport, Feifel, Maslow y Rogers, 1963, p. 14).

El enfoque existencialista de James se manifiesta por ejemplo cuando afirma que una verdad no pasará de ser una mera idea abstracta a menos que el sujeto a quien 
llegue pueda experimentarla o vivenciarla auténticamente en los distintos niveles de su ser. Sólo así constituirá una verdad operativa con capacidad transformadora. Ahora bien, May no comparte el extremismo sartriano reflejado por ejemplo en la declaración: "Somos lo que elegimos". De hecho May sigue reconociendo la validez del enfoque científico objetivo, "la validez de las consideraciones basadas en el condicionamiento, la formulación de los impulsos, el estudio de los distintos mecanismos, etcétera" (Ibidem), lo que rechaza es la pretensión de poder alcanzar una imagen aceptable sobre el ser humano a partir únicamente de tales métodos.

Refiriéndose a la conocida polémica entre Skinner y Rogers, considera que en ambos -aunque sus críticas se dirigen más bien hacia el primero- se produce un proceso de simplificación por no asumir las dos dimensiones del dilema. May no acepta que la experiencia subjetiva -y el control interno- queden plenamente subordinadas al control externo como hecho inevitable, aparte de las situaciones de laboratorio y hospital. Considera que la terapia ofrece pruebas constantes de que los individuos reaccionan ante su medio de una forma que tiene relación con su experiencia interna, con sus vivencias pasadas, y que realizan una interpretación del medio a través de sus símbolos, esperanzas y temores (May, 1978, p. 32). Sin embargo tampoco acepta la posición de Rogers en dicho debate al reducir lo significativo únicamente al control interno. La hipótesis de Rogers según la cual todo ser humano es, en el fondo, altamente racional, realista, siempre que haya podido experimentar una relación interpersonal satisfactoria -caracterizada por la "congruencia", el respeto y la aceptación de todos los sentimientos- lleva consigo el peligro de perder la capacidad de percibir el lado irracional y no libre del individuo. De hecho, en la experiencia terapéutica rogeriana con esquizofrénicos, llevada a cabo en la Universidad de Wisconsin, May y otros jueces de las grabaciones constataron la dificultad de los rogerianos para reconocer la presencia de comportamientos hostiles o agresivos, lo cual condujo incluso a Rogers a preguntarse si se debía a una falta de conciencia de los propios sentimientos negativos de los terapeutas. El mismo Rogers posteriormente hace declaraciones que manifiestan su acuerdo sustancial con la postura de May; y la necesidad de aprender a vivir aceptando el dilema:

Es mi convicción que parte de la vida moderna reside en enfrentarse a la paradoja que afirma que visto desde cierta perspectiva el hombre es una máquina compleja [...]. Por otra parte, en otra dimensión de su existencia el hombre es subjetivamente libre; su elección personal y su responsabilidad dan cuenta de su propia vida (Cit. en May, 1978, pp. 36s.).

\section{$3^{\circ}$ Atención a lo específicamente humano}

Otro logro de la Psicología Humanista es el de haber prestado especial atención a las experiencias y actividades específicamente humanas, por ejemplo: voluntad, amor, captación y vivencia de valores éticos, vacío existencial, experiencias transpersonales (horizontales y verticales), "experiencias cumbre", etcétera. 
En el famoso Congreso de Old Saybrook, en el que participaron los principales teóricos de la personalidad americanos como: Allport, Murray, Murphy, Kelly, como también los fundadores del Movimiento de la Psicología Humanista: Maslow, Rogers, y otros, no faltaron destacados conductistas como Hebb. Una de las críticas que éste dirigió a la Psicología Humanista se refirió al hecho de que se dedicase a enseñar aspectos de la vida humana como "aprender a vivir con los demás, aprender a hacer el amor, aprender a no crearse enemistades”. May le respondió así, según informó en la Conferencia Inaugural del Congreso de Psicología Humanista de Roma (1981):

No dudo que Hebb tenga razón cuando dice que estos aspectos no forman parte de la psicología tradicional, pero en lo que no estoy de acuerdo es que no formen parte de la psicología tal como ella debería ser. Si el porvenir probase que tuvo razón, que la psicología no puede tratar los problemas de la vida, del amor, de la amistad, entonces yo seré el primero en dejar la psicología, porque yo estoy allí para mis pacientes, para seres humanos, y rehúso subordinar los seres humanos a la ciencia (May, 1986, p. 34).

Con ello insistía en lo que ya desde el principio habían querido los fundadores del Movimiento: ocuparse de las experiencias específicamente humanas. Sobre éstas escribían algunos periodistas y algunos filósofos, pero en aquellos años no era normal que acaparasen la atención de psicólogos, psiquiatras y psicoterapeutas en sus investigaciones con ratas $u$ otros animales. $Y$ respecto a algunas experiencias especiales, como las espirituales o transpersonales, eran precipitadamente calificadas como psicopatologías por los psiquiatras.

Irvin Child, psicólogo científico y catedrático en la Universidad de Yale, reconocía lo siguiente:

El más grave de todos los defectos que desdora gran parte de la tradición científica en la investigación de la psicología es el conato por excluir del campo de la psicología la experiencia o conciencia (Child, 1975, p. 17).

Los psicólogos humanistas-existenciales, en sus teorías sobre los procesos psicológicos (emocionales, cognitivos, conductuales) y sobre la personalidad no dependían de tales limitaciones metodológicas.

\section{$4^{\circ}$ Recuperación del potencial de la voluntad}

Otro logro de la Psicología Humanista ha sido el de haber recuperado la importancia de la voluntad -no en sentido victoriano- como potencial nuclear de la conducta humana.

Es sorprendente cómo a lo largo de la historia de la psicología -primero filosófica y luego también científica- perduró la atención intelectual sobre el potencial humano volitivo -aparte de los sensoriales, cognitivos y afectivos. Sin embargo se produjo en la psicología un paréntesis largo, después de Freud, durante el cual desaparece el capítulo sobre la voluntad en los tratados de psicología.

Cuando William James publica en 1890 su obra fundamental Principios de 
Psicología, el tema de la voluntad ocupa todavía un espacio digno. En la edición española son setenta y ocho las páginas dedicadas a este potencial humano (sobre un total de mil cien páginas). El desprestigio del tema de la voluntad, que se fue produciendo después de Freud, no había influido todavía en James. Sin embargo, a medida que pasan los años, este tema va desapareciendo de los tratados de Psicología General. Señalemos alguno como muestra. Los Elementos de Psicología, de David Krech, Richard Crutchfield y Norman Livson, cuya primera edición apareció en 1969 y que en la edición española de 1973 ocupa 1087 páginas, no dedica ninguna al tema de la voluntad. Tampoco aparece ni siquiera nombrado este término en el detallado índice analítico de materias incluido en esta obra. Lo mismo ocurre con la valiosa obra de Edgar Vinacke, Psicología General, que apareció en 1972, y que en su edición española en dos volúmenes ocupa 1225 páginas. También aquí se da un silencio total sobre el concepto de voluntad. Y esto ocurre a pesar de que hemos elegido dos obras de las que aceptan y dedican atención al concepto holista de personalidad. Al menos en el caso de la obra de José Luis Pinillos, Principios de Psicología, ocupa un par de páginas -sobre un total de 731-, un apartado titulado Motivación y personalidad, en el que se permite llamar la atención sobre los peligros de este silencio.

En la medida en que los problemas de la acción humana se subsuman en las categorías motivacionales corrientes, los fenómenos de la decisión y la libertad corren el peligro de disolverse y quedar reducidos a una secuencia causal, donde la elección y el asentimiento tienen escasa cabida. Planteado en términos autorregulativos de necesidades, impulsos y reducción de los mismos, o de operantes refuerzos, la conducta motivada queda sujeta a unas leyes que, de suyo, tienden a la necesidad.

Sin embargo, es bien notorio que la acción voluntaria del hombre presenta unos grados de libertad poco compatibles, en principio, con el concepto de necesidad. La solución de esta antinomia de la psicología no se resuelve, desde luego, por el cómodo procedimiento de suprimir uno de sus términos; en la conducta del hombre coexisten ambos aspectos, el de la necesidad y el de la libertad, sólo que no en el mismo plano. La necesidad de los procesos motivacionales afecta a una variable de la conducta, pero ésta es algo distinto y superior a cada una de las variables que la integran. La conducta es la función de un sistema abierto, cuyas propiedades no pueden medirse con iguales criterios que los aplicables al estudio de los procesos aislados. $\mathrm{Y}$ es este hecho fundamental, el hecho de que la psicología ha propendido, por razones sin duda muy imperiosas, al estudio de procesos, más que al de la actividad general del sistema, lo que ha privado de lugar adecuado al problema de la libertad (Pinillos, 1975, pp. 545ss.).

Sin embargo, al margen de los paradigmas dominantes en los últimos decenios, en la psicología científica, no han faltado los psiquiatras y psicólogos que 
desde la investigación de la experiencia clínica han contribuido a revalorizar la actividad voluntaria y libre en la existencia humana. Entre éstos cabe destacar la contribución de Otto Rank (1976), que llega a titular su obra de madurez Will Therapy, Psicoterapia de la voluntad. Y que sitúa a ésta en el lugar que la libido ocupaba en Freud y el deseo de poder (o superación) en Adler, aunque con un concepto de voluntad que no anulaba sino que integraba estas tendencias. Está también Rollo May, psicoterapeuta humanista-existencial, que fue figura relevante por sus ponencias en los Congresos europeos de la Psicología Humanista, en los años setenta del pasado siglo, y que de entre sus publicaciones, donde aborda de forma más completa el tema de la voluntad humana es en Amor y voluntad. Las fuerzas que dan sentido a la vida, cuyo original en inglés, con el título de Love and will, se publicó en 1969. También hay que destacar la contribución del creador del modelo psicológico-humanista denominado Psicosíntesis -Roberto Assagiolique, aparte de lo que considera sobre esta cuestión en su obra principal Principi e metodi della Psicosintesi terapeutica (1973a), es sobre todo en The act of will (El acto de voluntad), 1973b, donde se ocupa exclusivamente de este tema. Cuestiones que aborda en esta obra son, entre otras: la voluntad fuerte, la voluntad sabia, la voluntad buena, la voluntad transpersonal, los estadios de la voluntad y la voluntad gozosa. Fuera del campo de la psicoterapia, y entre los tratados psicológicos que profundizan sobre la naturaleza y relevancia del potencial volitivo es el psicólogo fenomenológico Philipp Lersch el que reconocemos como más matizado, en los apartados en los que se ocupa de la voluntad en su magistral obra La estructura de la personalidad (1971). Finalmente, buscando entre los filósofos de los últimos decenios una contribución profunda sobre el tema, aquí se ha seleccionado como más matizada y convincente la obra del metafísico español Xavier Zubiri en su obra póstuma Sobre el sentimiento y la volición (1992). Queremos también mencionar aquí el excelente capítulo titulado "Dinámica: volición y libertad", del polifacético sabio Luis Cencillo (filósofo, antropólogo, psicoanalista independiente y psicólogo), en su obra Dialéctica del concreto humano (1975).

De las ideas de Rollo May sobre la voluntad, en especial las que expone en su libro Amor y voluntad. Las fuerzas humanas que dan sentido a la vida (1985) aquí se destacarán las siguientes, esquemáticamente:

\section{a) La descalificación freudiana de la voluntad}

Se puede reconocer como una contribución valiosa de Freud el que haya mostrado de forma convincente la futilidad y autoengaño que supone el concepto victoriano de 'fuerza de voluntad'. Freud mostró con claridad cómo en importantes áreas de la vida el protagonismo de las motivaciones y las conductas dependen no de la fuerza de la voluntad sino de impulsos, ansiedades, temores inconscientes y fuerzas instintuales.

Ahora bien, el conjunto de las aportaciones de Freud sobre este tema, centrado únicamente en una concepción distorsionada de la voluntad, acarreó una socavación 
del concepto genuino de voluntad sana, y con ello el socavamiento de la responsabilidad personal.

Las ideas de Freud sobre la voluntad, entendida únicamente en su versión degradada, dieron pie al desarrollo de una tendencia acentuada en el ser humano a mediados del siglo XX:

la tendencia a verse como un producto pasivo, irresoluto, del poderoso conjunto de pulsiones psicológicas (y como producto de fuerzas económicas, podríamos agregar, como lo demostró Marx en el plano socialeconómico mediante un análisis tan brillante como el de Freud) [...] En verdad, puede afirmarse que el núcleo central de la "neurosis" del hombre moderno está en el hecho de que se ve minada su experiencia de sí mismo como ser responsable, de que se ve socavada su voluntad y su capacidad de tomar decisiones (May, 1985, pp. 151s.).

\section{b) Debilitación de la voluntad tras el desarrollo tecnológico}

Los indudables logros técnicos producidos en los últimos decenios, con aplicaciones en distintas áreas de la vida, han dado pie a una posición pasiva en muchos de sus consumidores. " $¿ Y$ no consiste acaso lo esencial del acto de tomar una droga, lo mismo que cuando usamos las máquinas, en hacernos también pasivos? [...] Y es inevitable que así nuestras voluntades queden debilitadas, minadas" (May, ibidem, p. 153).

c) Psicoterapias productoras de impotencia volitiva

Tal como se ha llevado a la práctica el psicoanálisis, y también otras corrientes psicoterapéuticas en las que en el fondo se parte de la negación del potencial genuino de la voluntad en el ser humano sano, se ha contribuido a desarrollar la impotencia respecto a esta facultad y, por consiguiente, la incapacidad para decidir de forma humanizadora.

En las raíces de esta crisis [por el abandono del psicoanálisis por miembros sobresalientes de grupos freudianos] está la circunstancia de que el psicoanálisis no logra resolver el problema de la voluntad y la decisión [...]

Otras formas de psicoterapia tampoco escapan al problema que se le presenta al psicoanálisis, es decir, que el proceso psicoterapéutico mismo tiene tendencias intrínsecas que suscitan al paciente a renunciar a su posición de agente que decide (May, 1985, p. 160).

\section{d) La "antivoluntad" de Freud contra la "fuerza de voluntad" victoriana}

El sistema de antivoluntad de Freud parece haber sido una reacción contra un concepto victoriano de "fuerza de voluntad", predominante en su época, y que hay que reconocer inválido e insano, una interpretación distorsionada del genuino concepto clásico de voluntad. Era un concepto de voluntad voluntarista en la que 
las tendencias o deseos no quedaban integrados, orientados y armonizados, sino reprimidos.

La "fuerza de voluntad" designaba los arrogantes esfuerzos del hombre victoriano para manipular su ambiente y regir la naturaleza con mano de hierro, así como para manipularse él mismo y gobernar su propia vida como si fuera un objeto (May, Ibidem, p. 167).

\section{e) La voluntad sana como protectora de las tendencias}

Un concepto genuino de voluntad, que al parecer Freud desconoció, implica una dialéctica de la interrelación de voluntad y deseo. Podemos comprobar la coincidencia de estas afirmaciones de Rollo May con las del psicólogo fenomenólogo Lersch (1971) y el filósofo Zubiri (1992). Asimismo aparece bastante afinidad con la interpretación de Otto Rank (1976) -el que pasó de destacado colaborador de Freud a disidente-, y Roberto Assagioli (1989), el creador de la Psicosíntesis. Todos estos autores interesados por la revalorización de la voluntad no la entendían en su interpretación victoriana, que es la única que Freud, al parecer, conoció, y que le condujo a prescindir del reconocimiento de este potencial humano.

Puede considerarse que la voluntad y el deseo operan en polaridad. La voluntad requiere conciencia de uno mismo, el deseo no la requiere. La voluntad implica cierta posibilidad de elegir entre esto o aquello; el deseo no la implica. El deseo da a la voluntad calor, contenido, imaginación, la frescura de un juego de niños y riqueza. La voluntad presta al deseo orientación y madurez. La voluntad protege al deseo, permite que éste siga existiendo sin que se corran riesgos demasiado grandes. Pero sin el deseo la voluntad pierde su sangre vital y tiende a agotarse en la autocontradicción. Si se tiene sólo voluntad y no deseo nos hallamos frente al hombre neopuritano, victoriano, reseco. Si se tiene sólo deseo y no voluntad tenemos a la persona infantil, carente de libertad que es empujada por fuerzas ajenas a ella, la persona adulta que permanece siendo niño y que puede convertirse en el hombre robot (May, Ibidem, pp. 177s.).

Tras la atenta lectura de esta selección de ideas de Rollo May sobre la voluntad, constatamos que en aquellos procedimientos psicoterapéuticos del Análisis Transaccional -combinados con técnicas gestálticas y con actividad imaginaria-tal como quedan integrados en el modelo de Psicoterapia Integradora Humanista, se facilita la toma de decisiones -normalmente "redecisiones"- en las que no se da el peligro de un acto de voluntad "victoriano", despreocupado de proteger e integrar las tendencias o deseos. La decisión final-o "redecisión"-de la voluntad se ejecuta ciertamente desde el llamado en Análisis Transaccional "estado Adulto del yo", pero tras una escucha atenta de las necesidades, deseos o motivaciones del estado Niño. Se escuchan también los sentimientos, intuiciones y recomendaciones del estado Padre, a veces en conflicto con los del estado Niño. La decisión final no constituye un acto represor, sino una síntesis armonizadora e integradora que 
permite proteger, escuchar y atender las voces procedentes de la compleja singularidad de la persona y finalmente, descubrir cuál sea la decisión que, aquí y ahora, resulte auténtica (desde el Niño), protectora y nutricia para uno mismo y para otros (desde el Padre) y lúcida (desde el estado Adulto). Se trata de una decisión que no cae en ninguno de los dos peligros opuestos señalados por May, porque ni "pierde su sangre vital", ni constituye la decisión de una "persona infantil, carente de libertad".

A partir del reconocimiento del potencial humano de la voluntad, con capacidad para tomar decisiones libres - de no ser "hombres o mujeres robots", los psicólogos existencial-humanistas reconocen la importancia del sentimiento sano de culpa por parte de la persona que se percata de haber practicado -o esté practicando en la actualidad- conductas perjudiciales para el bienestar y el crecimiento personal de uno mismo, de otros, o de las instituciones. Asimismo, respecto a conductas y actitudes que van en contra del bien común. Valorando la contribución de Freud respecto a los perjuicios causados por la "culpa neurótica", los psicólogos humanistas de línea existencial no quieren caer en la ingenuidad rousseauniana que podemos denominar "inocencia neurótica". Ni quieren caer en el reduccionismo de reducir a trastornos psicopatológicos todas las conductas contrarias a la Ética, practicadas libremente.

\section{$5^{\circ}$ Admitir la creatividad y la capacidad de elección}

Se puede considerar un quinto logro de la Psicología Humanista el haber reconocido la capacidad de elección y de creatividad frente a concepciones psicológicas mecanicistas y deterministas preponderantes en los años cincuenta y sesenta del siglo XX.

Los iniciadores del movimiento de la Psicología Humanista -diferentes entre sí en sus concretas teorías psicológicas y psicoterapéuticas- compartían su clara discrepancia sobre los enfoques mecanicistas y deterministas predominantes en su entorno. La conducta humana consistía siempre, según esos enfoques, o en reacciones a partir de estímulos, siguiendo las leyes del condicionamiento clásico u operante (conductismo), o en la expresión o transformación de dos impulsos de base psicofisiológica (psicoanálisis).

Tal como muchos autores destacaban el poder de esos factores en toda trayectoria vital humana, daba la impresión de que se implicaba una imagen de "hombre robot" (o de organismo meramente reactivo) (Bertalanffy, 1976), y de que resultaba difícil admitir la posibilidad de decisiones lúcidas y libres, a no ser que se tratase de vidas humanas excepcionales y que habrían requerido largos años de un psicoanálisis o una psicoterapia profunda. Concepción que Murray en su crítica la describió con claridad en la forma que ya se señaló anteriormente, cuando se negaba a aceptar el ser humano entendido en forma determinista como una computadora, un niño o un animal, y en que no hay "ningún fundamento en absoluto para la menor esperanza de que la raza humana pudiera salvarse de la fatalidad a la que hoy se 
enfrenta" (Murray, cit en Bertalanffy, 1976, pp. 216.).

El biólogo y teórico de la ciencia Ludwig von Bertalanffy-creador de la Teoría General de los Sistemas-que, a pesar de las características de su entorno científico, se mantuvo al margen de todo reduccionismo fisiológico al explicar el psiquismo humano, se lamentó del determinismo implicado en la mayoría de las teorías psicológicas de su época.

El modelo de hombre como robot ha sido inherente a todos los campos de la psicología y la psicopatología, y a teorías y sistemas por lo demás diferentes o antagónicos: a la teoría de E-R del comportamiento, a la teoría cognoscitiva en lo que ha sido llamado el "dogma de la inmaculada percepción", a las teorías del aprendizaje-pavlovianas, skinnerianas, o con variables de por medio-, a diversas teorías de la personalidad, al conductismo, el psicoanálisis, los conceptos cibernéticos en neurofisiología y en psicología, y así sucesivamente (Bertalanffy 1976, p. 200).

Y se congratuló de las primeras aportaciones de línea humanista presente también en las escuelas neofreudianas y nuevos enfoques cognitivos, entre otros. Así, resulta necesario un nuevo modelo del hombre, y en verdad va surgiendo lentamente de tendencias recientes en psicología humanística y organísmica. El hincapié en el lado creador de los seres humanos, en la importancia de las diferencias individuales, en aspectos que no son utilitarios y están más allá $\mathrm{d}$ los valores biológicos de subsistencia y supervivencia; todo esto y más está implícito en el modelo del organismo activo. Estas nociones son fundamentales en la reorientación de la psicología que se está presentando hoy; de ahí el creciente interés que despierta la teoría general de los sistemas en psicología y especialmente en psiquiatría.

En contraste con el modelo del organismo reactivo expresado por el esquema de E-R - la conducta como satisfacción de necesidades, relajamiento de tensiones, restablecimiento del equilibrio homeostático, interpretaciones utilitarias y ambientalistas, etcétera-, preferimos considerar el organismo psicofísico como un sistema primariamente activo. Creo que no hay otra manera de considerar las actividades humanas. Por mi parte, soy incapaz de ver, por ejemplo, cómo las actividades culturales y creadoras de toda índole pueden considerarse "respuestas a estímulos", "satisfacción de necesidades biológicas", "restablecimiento de la homeostasis", y así por el estilo (Ibidem, pp. 202s.).

En la primera obra colectiva importante de autores implicados en el surgimiento de la Psicología Humanista - editada por James F.T. Bugental (1967), Challenges of Humanistic Psychology- no faltó un capítulo de Bertalanffy: The world of science and the world of value. En él se denunciaba los defectos de una educación -en sus distintos niveles, que no contribuía a formar personas libres, por centrar todas sus metas en lo utilitario, que al final tampoco tenía las consecuencias 
prácticas esperadas. Refiriéndose a una educación para el cultivo de la libertad y la vivencia personal de valores decía: "La meta de la educación [...] no es producir autómatas sociales mantenido en adaptación y sumisión por condicionamiento" (Bertalanffy, 1974, p 343).

Actualmente se puede afirmar que los presupuestos antropológicos mecanicistas y deterministas predominantes a mediados del siglo pasado han experimentado una notable disminución en las teorías principales del colectivo de los psicólogos. Los sucesores del conductismo, me refiero a los conductual-cognitivos y a los cognitivo constructivistas, han mantenido de aquél sus procedimientos metodológicos experimentales y observacionales, pero no aceptaron la marginación de los procesos mentales en sus investigaciones, y en su mayoría no comparten el rígido enfoque mecanicista y determinista de aquéllos. Asimismo, buena parte de los psicoanalistas -aunque eviten declararlo dada su veneración hacia su maestro Freud-se han ido distanciando notablemente de algunos de sus contenidos teóricos, entre otros de los que venían a anular -o casi- la capacidad humana de libertad. Así ocurrió ya por parte de Karen Horney, Erich Fromm, y Harry Sullivan, y antes que ellos, en Alfred Adler, Carl Jung y Otto Rank, importantes colaboradores de Freud que luego se separaron de él.

Si bien estos autores -y podemos añadir a J.L. Moreno, y a los explícitamente implicados en la Psicología Humanista, por ejemplo May, Maslow, Rogers, Perls, Berne, y Lowen, entre muchos otros, todos ellos reconocen la relevancia de las experiencias emocionales de la infancia-derivadas de las conductas parentales-en la evolución posterior del sujeto; aunque conceden un carácter no determinista a tales influjos. Atribuyen a Freud una visión excesivamente pesimista o fatalista sobre los efectos que puedan producirse en la trayectoria personal a partir de los errores de los padres, entre otros. En el tratamiento terapéutico, en la mayoría de estos autores, no importa mucho indagar qué pasó exactamente en el pasado infantil del sujeto, sino qué es lo que hoy percibe sobre aquel pasado, coincida mucho o poco con la realidad histórica.

Se ha hecho referencia a las corrientes cognitiva-constructivistas y neopsicoanalistas como testimonios del distanciamiento de estos colectivos respecto a posturas mecanicistas y deterministas. Pero hay que considerar que en esta evolución han jugado un papel claramente preponderante -y de forma más explícita- una serie de los iniciadores del Movimiento psicológico humanista, y de los sucesivos creadores de modelos terapéuticos de esta línea.

Ejemplo de ello es la recuperación y revalorización -como antes se ha dichodel potencial psicológico de la voluntad, con capacidad de decisiones libres, por parte de May (1985), Berne (1973), Assagioli (1989) entre otros. Y con ello también la recuperación del sentido de responsabilidad para poder experimentar el sentimiento sano de culpa (distinto de la culpa neurótica). Conceptos, tanto el de la voluntad como el del sentimiento sano de culpa, que habían desaparecido de la Psicología, hecho comprensible partiendo de la base de la inexistencia de una 
actividad libre en la conducta humana.

Suprimida la libertad -o reducida a un acontecimiento muy excepcionaldesaparecía la creatividad, de la que Maslow decía que tenía la impresión de que cada vez ese término y el de autorrealización están más cerca, e incluso que podrían ser conceptos idénticos (Maslow, 1983).

\section{$6^{0}$ Reconocimiento de la variabilidad de las motivaciones}

También hay que entender como un logro el haber reconocido la variabilidad de aquellas motivaciones que no dependen de los impulsos básicos psicofisiológicos.

La aportación de Allport sobre esta cuestión fue compartida por muchos psicólogos humanistas-existenciales. Distanciándose del psicoanálisis y del conductismo inicial, entendieron que no toda motivación de la persona adulta es evolución de una motivación presente ya en la infancia, sino que se admite la capacidad de la persona para ampliar intereses y motivaciones que no sean necesariamente los diferentes disfraces de una o dos pulsiones originarias. En el ser humano no se dan sólo necesidades, hay también aspiraciones. Estas son, en la persona madura, peculiares, vividas con fidelidad a sí misma, y componentes de su proyecto existencial.

\section{$7^{0}$ Admitir la posibilidad de "metamotivaciones" en el ser humano}

El concepto de metamotivación introducido por Maslow (1975, 1982, 1983) coincide en parte con lo que Philip Lersch (1971) había denominado "tendencias transitivas", que más allá de las tendencias de la vitalidad y del yo individual son tendencias genuinas del ser humano que no son coincidentes con sublimación de otras tendencias, sino que tienen entidad propia. En la práctica terapéutica se concreta en la distinción entre la persona que presenta una patología y la que presenta una metapatología. Se considera que esta patología es igualmente causa de sufrimiento y frecuentemente, como indica Fromm (1966), es reprimida por una cultura social neurótica, que condena el exceso de "biofilia" y las tendencias a la autorrealización -que van más allá de los límites que la sociedad puede digerir-con el aislamiento y la incomprensión.

Maslow tuvo que reconocer, en su etapa final, que no se cumplía en muchos casos su hipótesis de que toda persona que llegase a tener suficientemente atendidas sus necesidades básicas -fisiológicas, de seguridad, de afecto y afiliación, de valoración- pasaba de forma automática a experimentar las metamotivaciones. A la pregunta que le planteó Frick (1984) en una entrevista: "Creo que esto representa un cambio importante en su posición teórica. ¿Es así?”, Maslow le respondió:

Sí, es una sorpresa. Siempre supuse, como lo hizo Freud -quizá lo aprendí de Freud-que, si se descartaba lo inservible, y las neurosis y los desechos, etc., entonces la persona florecería y encontraría su propio camino. A veces me toca comprobar, en especial con los jóvenes, que no es así a veces (Frick, 1986, p. 52). 
Considero de interés la hipótesis propuesta por Frick para dar respuesta a este incumplimiento de la teoría de Maslow, revisando la suposición de éste sobre el carácter más bien instintoide del paso a las metamotivaciones.

Frick propone un "modelo conceptual" del crecimiento personal, según el cual "una orientación conceptual centrada en conceptos que realzan el crecimiento altera la propia percepción de uno mismo y sus potencialidades" (Ibidem, p. 56). Se adhiere a la hipótesis de Weisskopf-Joelson (1968) que sostiene que el disponer de una interpretación de la vida a partir de algún sistema filosófico o de creencias facilita a ésta una estructura y significado. Frick propone cinco conceptos que considera importantes como orientadores para un incremento del crecimiento, en concreto: el individuo ideal, la autonomía, la vida como proceso, la integridad interpersonal y la comunidad, y el terreno transpersonal.

Dichos conceptos dan a conocer estas fuerzas latentes e inarticuladas y, una vez liberados, proporcionan una consciente influencia sobre su expresión y dirección. Así los conceptos que realzan el crecimiento devienen una fuerte fuerza motivacional para la auto-actualización, en su propio derecho (Frick, 1986, p. 57).

Esta hipótesis de Frick parece de especial interés para posibles investigaciones. Siempre y cuando no deje de incluir -precediendo o acompañando a la conceptualización- el recurso de la actividad imaginaria -de las visualizaciones mentales- dado su comprobado poder movilizador, superior al de los conceptos abstractos.

\section{$8^{\circ}$ Destacar la importancia del proyecto vital}

Otro acierto de la Psicología Humanista es el de haber concedido importancia al proyecto vital de la persona -consciente o inconsciente- y a la búsqueda de sentido.

Encontramos aquí otra experiencia humana a la que tanto los conductistas como los freudianos no concedían interés psicológico. En cambio el sector existencial de los psicólogos humanistas lo consideraron primordial, asumiendo las líneas básicas del pensamiento de May $(1974,1978,1988)$ y Frankl $(1980,1988$, 1990). Actualizando, de acuerdo con Rychlak (1988) la clasificación de las cuatro causas aristotélicas, y no limitándose-como ha sido muy frecuente al investigar las causas de las conductas psicopatológicas y de los cambios terapéuticos-a las causas "material" y "eficiente", se concede relevancia, a las causas "formal" y, en especial, a la causa "final".

El énfasis concedido a esta última nos aproxima a algunas teorías y aportaciones de Adler y se refleja, en el plano psicoterapéutico, en la importancia que concede a lo que el Análisis Transaccional denomina "análisis del guión vital", incluyendo dentro de los objetivos globales de la psicoterapia -si es armónico con la demanda del paciente o cliente- la posibilidad de sustitución de un proyecto construido en forma rígida (lo que propiamente es el "guión") o la ausencia de proyecto (ausencia 
de guión, o guión de "ir tirando" en términos analítico-transaccionales) por un proyecto flexible elegido desde la libertad y lucidez que en ese momento de su vida es capaz ("salirse del guión", o "guión de triunfador).

En cuanto a la relevancia dada a la "causa formal", se manifiesta en la práctica terapéutica a partir de la concepción de un modelo basado, ante todo, en un análisis del proceso (o "forma"), que el sujeto desarrolla para lograr aquellos objetivos, a semejanza de la perspectiva de la Psicoterapia de la Gestalt, la Psicología de los Constructos Personales de Kelly y la Psicoterapia Postrogeriana de Egan.

\section{$9^{\circ}$ Admitir modelos terapéuticos abiertos}

También hay que considerar un logro de la Psicología Humanista el haber admitido la posibilidad de modelos psicoterapéuticos metodológicamente integradores respecto a teorías y/o procedimientos de intervención, es decir, modelos terapéuticos como "sistemas abiertos".

Una parte de los psicólogos humanistas-existenciales consideran que no existe en la actualidad un modelo de psicoterapia que sea válido para todas las personas, problemas y circunstancias, y por ello se sienten llamados a mantenerse receptivos y dialogantes respecto a las aportaciones que desde otros modelos o paradigmas pudieran ser integradas en forma coherente y que pudieran hacer más efectivo el tratamiento. A la vez ejercitan una actitud vigilante respecto a las propias afirmaciones, y de atención a contrastarlas con la constante retroalimentación que la experiencia va proporcionando. La integración con otros modelos o teorías se podrá dar de forma diferenciada, pudiendo integrar algunos modelos en forma prácticamente total, respecto a alguna de sus posibles escuelas o variantes, o casi total respecto a los que se diferencian por algunos matices de tipo metateórico, o teórico. Respecto a otros se pueden integrar a un nivel inferior, estratégico y desde el punto de vista técnico de los procedimientos de intervención. Cabe la posibilidad de un eclecticismo tecnológico, es decir, la libertad de tomar de cualquier modelo las técnicas que se considere que -aún sin tener el significado que el contexto de su modelo le confiere- puedan ser redefinidas en forma coherente e integrada, y tengan un pronóstico de efectividad dentro del propio modelo. Desde sus orígenes, esta actitud metodológicamente integradora fue practicada por algunas escuelas de la Psicoterapia de la Gestalt, del Análisis Transaccional, y de la Psicosíntesis, entre otras. En el modelo de Psicoterapia Integradora Humanista (Gimeno-Bayón y Rosal, 2001; 2016), se integran teorías y/o técnicas procedentes de más de veinte modelos. Esta práctica que en los años cincuenta y sesenta del pasado siglo fue descalificada por los partidarios, entonces, de escuelas autosuficientes, hoy se ha extendido también entre algunos psicólogos conductual-cognitivos y psicoanalíticos.

\section{$10^{\circ}$ Priorizar el vínculo terapéutico}

En los años que surgió el Movimiento de la Psicología Humanista, al tema de los requisitos para una buena relación terapéutica no se le concedía un carácter 
prioritario. Otto Rank fue un precursor de esta cuestión, a la vez que el introductor del término "psicoterapia", al cual sucedió Rogers. A partir de éste fueron muchos los psicólogos humanistas de diferentes métodos psicoterapéuticos que reconocieron la importancia de las tres actitudes rogerianas de la aceptación incondicional positiva, la empatía y la autenticidad, no sólo a título de exigencias éticas que enmarquen la relación sino como indispensables para que pueda surgir una alianza eficaz (Lafferty, Beutler y Crago, 1990). A la vez se entendió que la vinculación terapéutica debe estar atenta, en forma idiosincrásica, a las perturbaciones en el vínculo que presente la persona, a las hipotéticas causas de la misma, y a proporcionarle unas experiencias globales (emocionales, cognitivas, corporales, práxicas, interaccionales) diferentes de aquéllas que contribuyeron a la creación de la perturbación y que sirviesen para que el paciente construyese en forma alternativa sus interacciones.

Fueron muchos otros los autores de modelos psicoterapéuticos humanistas que se ocuparon de esta cuestión, y que señalaron otras diversas actitudes favorecedoras de la adecuada relación terapéutica, entre otros los de la Psicoterapia Existencial, la Psicoterapia de la Gestalt, y el Análisis Transaccional. En un artículo sobre esta cuestión (1986) ya se hizo referencia a las siguientes once-incluidas las tres rogerianas-: 1) Considerar al cliente como una personalidad singular e irrepetible; 2) Confianza en las capacidades psíquicas del cliente para un comportamiento creativo en el proceso terapéutico; 3) Ser consciente de los límites de todo modelo psicoterapéutico; 4) Conciencia de las propias limitaciones psíquicas; 5) Evitación de la actitud de Salvador, en el sentido en que Karpman (1968), acuñó este término; 6) Actitud no favorecedora del establecimiento de una neurosis de transferencia entre terapeuta y cliente; 7) Apertura o receptividad respecto a cualquiera de las dimensiones de la conducta del cliente, y a las vivencias emocionales y cognitivo-intuitivas de la creatividad del terapeuta; 8) Comprensión empática; 9) Resonancia somática en el sentido en que Boadella se refiere a ésta:

En mi trabajo el terapeuta trata de estar en contacto con sus propios sentimientos, manteniendo su propio cuerpo vivo, como un foco de sintonización con el paciente. El cuerpo del terapeuta es como un sintonizador para ser sensible a las señales que da el paciente que no son verbales y para ser transmisor limpio de señales no verbales al paciente, o sea que mantiene su cuerpo abierto a recibir y a transmitir (Boadella, 1985, p. 67).

10) Consideración positiva incondicional, o calidez no posesiva; 11) La congruencia o autenticidad.

Después de cincuenta y pico años, parece que el reconocimiento de la importancia de los requisitos para una buena relación terapéutica es algo que comparten una proporción importante de los profesionales, se encuentren o no relacionados con la Psicología Humanista. 


\section{$11^{\circ}$ Facilitar la vivencia experiencial en la sesión}

Otro logro a destacar es el de haber facilitado la actividad experiencial en la sesión terapéutica, proponiendo para ello la realización de ejercicios adecuados para cada caso.

Con la excepción de la Terapia Centrada en la Persona, de Carl Rogers, la gran mayoría de psicoterapeutas humanistas recomiendan al terapeuta un papel activo que, a la vez que escucha empáticamente al cliente, interacciona con él haciéndole propuestas de exploración concretas, separándose en ello de la no directividad del enfoque rogeriano y situándose a medio camino entre esa no-directividad y el autoritarismo, es decir, lo que se llama un estilo "democrático" que -por otra parteparece el más efectivo (Lewin, Lippit y White, 1939), al menos en lo que se refiere a la psicoterapia grupal.

Mayoría de psicoterapeutas humanistas basan la eficacia del cambio terapéutico en el hecho de proponer al cliente, a lo largo de las sesiones, experiencias en el "aquí y ahora" que pongan de relieve la inconsistencia o disfuncionalidad de sus patrones de comportamiento y faciliten el hallazgo de otros nuevos más funcionales. Este tipo de confrontación no se realiza desde la directividad del terapeuta ni desde interpretaciones externas, sino desde el propio estilo del vínculo, y desde planteamientos indirectos, tales como el estímulo hacia la exploración de nuevos aspectos, o las preguntas dirigidas a que se repare en aquellos niveles de su experiencia que está obviando, o guiándole hacia una nueva elaboración subjetiva coherente y, en definitiva, llevándole a que integre los aspectos escindidos de sí mismo y de su mundo interno.

\section{$12^{\circ}$ Resaltar el papel del hemisferio derecho}

Haber concedido una importancia relevante, en la terapia, al papel de las funciones relacionadas con el hemisferio cerebral derecho es otro de los logros de la Psicología Humanista.

Esto se debe a que en las psicoterapias humanistas -en mayoría de los modelos- se considera que la empatía emocional, la actividad imaginaria, y la intuición son procesos psicológicos con gran potencia en la sesión terapéutica. La importancia de las emociones en el proceso ha sido enfatizada recientemente por Greenberg (Greenberg y Korman, 1993; Greenberg, Rice y Elliot, 1996). Aparte de ello, es en este nivel, junto con el de relación, en el que se suelen plantear las quejas -más en términos de "me siento mal" que en los de "pienso en forma disfuncional"y es habitual ese énfasis en las terapias que se mueven en el marco de la Psicología Humanista, al igual que la dimensión corporal. Lo mismo ocurre con la intuición, tanto desde las técnicas gestálticas que fomentan un corte de la visión lógica de la realidad para romper la relación fondo/figura que ha quedado rigidificada $-\mathrm{y}$ permitir la reorganización de la experiencia mediante un proceso de "pensamiento productivo" (utilizando la terminología de Wertheimer, 1968), como desde el uso de ese pensamiento intuitivo -el llamado Pequeño Profesor, o también "la visión 
marciana" (Berne, 1974) - y la fantasía en el Análisis Transaccional, y en las oniroterapias (los modelos terapéuticos que utilizan con gran predominio los procedimientos de intervención con imágenes y fantasía). Sobre la implicación de los potenciales del hemisferio cerebral derecho en la psicoterapia y en especial el poder terapéutico de la actividad imaginaria, ya se informó en otros lugares (Rosal, 2013 y 2015).

El creciente reconocimiento de la validez de la teoría sobre la diferenciación de funciones de los hemisferios cerebrales (Bogen, 1969; Gazzaniga, 1970; Gazzaniga y Ledoux, 1978; Kimura, 1973; Ley, 1983, 1984; Ley y Bryden, 1979; Sperry y Gazzaniga, 1967), ha tenido, como una de sus manifestaciones, que se le concediera a Roger W. Sperry, por los logros de sus investigaciones en esta materia, el premio Nobel de Fisiología y Medicina en 1981.

Estos científicos y, en especial, Sperry deben desconocer el gran favor que nos han hecho a los psicoterapeutas existencial-humanistas. Efectivamente, la gran mayoría hemos trabajado, en la sesión terapéutica, con un ejercicio prioritario de potenciales psicológicos dependientes principalmente del hemisferio cerebral derecho. Con el respeto que, en el colectivo de los científicos, se concede a los premios Nobel, ya no podrán decir que esta teoría es una muestra más de la ingenuidad o el esoterismo de aquéllos.

\section{$13^{\circ}$ Valorar la eficacia de los procedimientos con fantasía}

Hay que destacar también, como logro interesante de la Psicología Humanista, el de haber reconocido el poder terapéutico de los procedimientos de intervención con imágenes y fantasía.

Una de las manifestaciones de la creatividad tecnológica en los modelos psicoterapéuticos humanistas se ha traducido en la gran variedad de técnicas terapéuticas con actividad imaginaria, a pesar de que, como se ha subrayado, en general hayan concedido prioridad a la importancia de las actitudes requeridas para la relación terapéutica. De esta forma se comprueba la existencia de tres vías de comunicación en la sesión terapéutica: la vía verbal de la escucha y la palabra, la vía imaginaria, y la psicocorporal, a la que se refiere el punto siguiente.

El resurgimiento del interés hacia las imágenes por parte de los psicólogos científicos dio lugar, especialmente a partir de los años sesenta del siglo pasado, a un volumen extraordinario de investigaciones teóricas y experimentales sobre el tema. Un dato significativo de este hecho lo constituyó la relación de más de siete mil referencias bibliográficas -correspondientes al período de 1977 a 1991-que aparecen en la Imagery Bibliography, publicada en el Journal of Mental Imagery, 18 ( 1 y 2), editado por Akter Ashen en 1994. Este hecho que Holt (1972) denominó el "retorno de las desterradas" ocurrió después de haberse eliminado como objeto de interés psicológico de investigación por influencia de Watson (1913), que las había descalificado como "quimeras". Las imágenes lógicamente se incluían entre esa serie de "cuestiones especulativas", o "conceptos mentalistas", que como no era 
posible someter al tratamiento experimental convencional era lamentable, según Watson, que anteriormente hubiesen acaparado la atención de muchos psicólogos. Rogó a éstos que se abstuviesen de ocuparse de ellas, y tal ruego fue objeto de un acatamiento general por parte de los investigadores durante más de treinta años. Consultando los Psychological Abstracts correspondientes al periodo de 1920 a 1950 el tema de las imagery está prácticamente ausente.

al rechazar el concepto de imagen, por su carácter mentalista y porque no hay ninguna prueba experimental que permita afirmar la significación funcional de la imagen en la conducta, Watson (1930) propuso su propia solución, que consistía en considerar las respuestas verbales implícitas (o mejor dicho, los "procesos sensoriales localizados en la laringe") como el mecanismo responsables de las funciones atribuidas hasta entonces a la imagen en las conductas psicológicas (Denis, 1984, p.14).

A partir de estas declaraciones de la cabeza visible del cuerpo de psicólogos investigadores se comprende, como señalan Sheikh y Panagiotou (1975), y Denis (1984) que los psicólogos experimentales ignorasen la realidad de las imágenes y se centrasen exclusivamente en las asociaciones lingüísticas y conductuales. Durante unos treinta años como ha destacado Holt (1964) las imágenes "fueron condenadas al ostracismo" y pasaron de ser uno de los conceptos más relevantes en la psicología introspeccionista, a ser "fantasmas de sensaciones" (ghosts of sensations) sin ninguna importancia funcional. "La psicología introspectiva desapareció, y el estudio de las imágenes mentales se desvaneció con ella. Durante unos 30 áridos años los psicólogos respetables consideraron casi indecente hablar de los procesos mentales" (Neisser, 1972, cit. en Richardson, 1980, p.6).

En la nueva fase de reconocimiento de la actividad imaginaria en terapia se utilizan, principalmente, imágenes de la memoria, imágenes de la fantasía, e imágenes eidéticas estructurales. "La función clínica de la imagen eidética parece ser la de preservar, repetir e intensificar la experiencia y entonces permitir que el individuo perfeccione sus respuestas adaptativas" (Ashen, 1977, p. 34).

A finales de los años cincuenta y primeros de los sesenta debió ser muy excepcional que modelos terapéuticos con importante recurso a las técnicas con imágenes pudiesen dar a conocer sus innovaciones terapéuticas en los congresos o revistas dirigidos por conductistas o psicoanalistas. Modelos que han trabajado principalmente a partir de la espontaneidad imaginaria habían sido, entre otros, Ensueño Dirigido de Robert Desoille (1938, 1973, 1974). Imaginería afectiva de Hans Leuner (1969, 1977, 1978), Psicoterapia eidética de Akter Ashen (1968, 1972, 1977), Psicoterapia de la imaginación de Joseph E. Shorr (1972, 1974a, 1974b).

Todos ellos ofrecían métodos terapéuticos imaginarios que muchos psicólogos humanistas valoraron y acogieron. Entre los modelos vinculados al Movimiento de la Psicología Humanista ha sido especialmente creativa la Psicosíntesis de Roberto Assagioli (Assagioli, 1973; Crampton, 1969, 1974, 1975, 1981; Ferrucci, 
1987). Asimismo ha sido muy tenida en cuenta la actividad imaginaria en la Psicoterapia de la Gestalt, en el Análisis Transaccional y algo menos en el Focusing de Gendlin. En el modelo de Psicoterapia Integradora Humanista probablemente en no menos de un tercio de las sesiones, como media, los terapeutas aplican alguna técnica con imágenes y fantasía, incluida la del "diálogo con la silla vacía" de Perls. Pienso que el éxito de este tipo de recursos puede haber sido la causa de su utilización por terapeutas conductual-cognitivos y por algunos psicoanalistas.

Una variedad de técnicas conductual-cognitivas que, paradójicamente, a pesar de ser acuñadas por seguidores -aunque heterodoxos- de Watson, han sido protagonistas importantes en el proceso de revalorización del uso terapéutico de las imágenes en la comunidad de los psicólogos científicos.

\section{$14^{\circ}$ Comprender la eficacia de los procedimientos psicocorporales}

Haber reconocido el poder terapéutico de procedimientos psicocorporales, aparte de las vías verbal e imaginaria, es un logro también muy específico de la Psicología Humanista.

De los más de cien modelos o métodos psicocorporales existentes (ciento diez en la enumeración de Gimeno-Bayón, 2013), muchos psicoterapeutas humanistas, o bien ejercen su actividad terapéutica en el marco de uno de estos modelos Bioenergética, Biosíntesis, Focusing, Rolfing, Psicodanza, etcétera-, o bien integran una selección de procedimientos corporales en el suyo, logrando con ello aumentar el poder terapéutico de las vías verbal e imaginaria.

Este tipo de enfoque responde a la convicción de que el ser humano es una unidad psicofísica en la que las dimensiones somática y psicológica son expresiones de una misma realidad, plasmada en esos dos niveles.

\section{$15^{\circ}$ Creación de nuevos paradigmas de investigación}

Un último logro a destacar es el haber aportado la metodología de nuevos paradigmas de la investigación cuando los convencionales no resultan idóneos para verificar algunas hipótesis.

La primera obra colectiva importante de autores implicados en el Movimiento de la Psicología Humanista se publicó en 1967, siendo el coordinador James F.T. Bugental, con el título Challenges of Humanistic Psychology. En ella hay un porcentaje importante de capítulos que hacen referencia a la investigación científica. La parte tercera, titulada Research areas and methods contiene siete capítulos. La parte cuarta, titulada Some research products, seis capítulos. Es decir, desde sus inicios, la Psicología Humanista ofrece el testimonio de psicólogos con vocación de investigación científica, no sólo de psicoterapeutas. Esto ocurre sobre todo en aquellos países como los Estados Unidos en los que son abundantes la Universidades que tratan con respeto a los psicólogos humanistas. No ocurre así en España, salvo en algunos casos concretos.

Pero como logro principal respecto a esta cuestión hay que destacar la obra 
Human Inquiry. A Sourcebook of New Paradigm Research, editada por Peter Reason y John Rowan en 1981 y reimpresa en 1985.

Se señalan a continuación algunos de los títulos de sus cuarenta capítulos:

- Philosophical basis for a new paradigm, de John Heron

- The subjective side of Science, de Jan Mitroff

- The general and the unique in psychological science, de G. W. Allport

- The psychology of science, de Abraham Maslow

- On making sense, de John Rowan y Peter Reason

- Experiential research methodology, de John Heron

- Personal construct theory and research, de Donald Bannister

- The interviewing process re-examined, de Fred Massarik

- Heuristic research, de Clark Moustakas

- Issues of validity in new paradigm research, de Peter Reason y John Rowan

- Sharing the research work: participative research and its role demands, de Max Elden

- Implementing new paradigm research: a model for training and practice, de Shulamit Reinharz

A continuación, se indican algunos de los criterios del Nuevo Paradigma que se han tratado de cumplir en el Instituto Erich Fromm de Psicoterapia Integradora Humanista (desde el que escribe el autor), cuando ha realizado alguna investigación:

1. El trabajo clínico ha reunido normalmente las características de una investigación cooperativa, en la línea de lo reclamado entre otros por Heron (1985a): "En la forma completa de este enfoque, no sólo será el sujeto plenamente un coinvestigador sino que el investigador será también un cosujeto, que participa plenamente en la acción y experiencia que ha de investigarse" (Heron, 1985a, p.195).

2. La capacidad de alcanzar una elevada calidad de conciencia, por parte del psicoterapeuta y del investigador es un requisito para la validez de una investigación según proponen, p.e., Reason (1985), Heron (1985b), y Maslow (1966). Reason y Rowan establecen ocho principios para garantizar la validez en la investigación del nuevo paradigma, relacionándose los dos primeros con esta cuestión. Los formulan con estos términos:

Una investigación válida se apoya sobre todo en una conciencia de alta calidad por parte de los coinvestigadores (Reason y Rowan, 1985, p.245). Dicha conciencia de alta calidad sólo puede mantenerse si los coinvestigadores se implican en algún método sistemático de desarrollo personal e interpersonal (Ibidem, p.246).

Sin haber vivido la experiencia de profundizar en el propio autoconocimiento y sin algún tipo de trabajo personal sistemático que haya facilitado entrar en contacto con procesos internos inconscientes, estos autores consideran difícil 
alcanzar la capacidad de atención y de conciencia requerida para una investigación válida sobre los procesos psicológicos de otros sujetos.

Maslow se refiere también al peculiar estado de la mente que requieren el terapeuta y el investigador, para comprender lo que ocurre en la mente de estos sujetos. Solamente este peculiar modo de atención puede ser fiel al enfoque holista -en contraposición a reduccionista- requerido por el nuevo paradigma. Con su lenguaje más bien informal y exagerado, lo resume en estos términos:

Todo clínico sabe que en el proceso de conocer a otra persona es mejor mantener su cerebro fuera del camino, y escuchar de forma total, encontrarse totalmente absorbido, receptivo, pasivo, paciente, y expectante más bien que apremiante, rápido e impaciente. No ayuda estar midiendo, preguntándose, calculando o probando nuestras teorías categorizando o clasificando. Si su cerebro está demasiado ocupado, usted no puede escuchar y ver bien. El término de Freud atención flotante describe bien esta clase de conocimiento de otra persona que no interfiere, global, receptivo, que espera (Maslow, 1966, cit. por Rowan, 1985, p.83).

3 . El conocimiento experiencial es requerido, en la ciencia del nuevo paradigma, como complemento del conocimiento proposicional y del conocimiento práctico. Tanto Heron como Reason lo reclaman, como también Harré, Rowan, Torbert y Reinharz, entre los autores que colaboran en la obra ya citada de Reason y Rowan (1985):

Conocimiento experiencial es conocer una entidad - persona, lugar, pensamiento, proceso, etc.- en un encuentro e interacción cara a cara. Es conocer a una persona o cosa a través de un trato prolongado. La investigación empírica, precisamente porque es empírica, requiere necesariamente cierto grado de conocimiento experiencial sobre las personas y objetos sobre los que trata la investigación. Las conclusiones del investigador son proposiciones sobre personas o cosas de los cuales él o ella ha tenido un conocimiento experiencial a través de un encuentro directo (Heron, 1985b, p.27).

De los principios de Reason y Rowan, ya citados, para la validez de la investigación, el quinto contiene también esta reclamación: "La investigación válida implica una interacción sutil entre diferentes formas de conocimiento" (Reason y Rowan, 1985, p.249), en la que se refiere al logro de un conocimiento más "denso" y más "sustancial" cuando incluye las cuatro formas de conocimiento experiencial, práctico, presentacional y proposicional. Torbert subraya también este requisito con particular énfasis:

De acuerdo con el nuevo modelo de investigación, un sistema de actuación que no se ocupe de un estudio de sí mismo experiencial no puede ni producir ni reunir datos válidos debido a las incongruencias no examinadas en el interior de su experiencia. Tal sistema distorsionará los datos tanto de forma deliberada como sin querer y resistirá procesar un feedback que 
identifique las incongruencias (Torbert, 1985, p.150).

El requisito del conocimiento experiencial, e incluso la preferencia del mismo, en este nuevo paradigma, no margina el tipo de conocimiento en el que se ha centrado la ciencia occidental: "Mi tesis es que este conocimiento experiencial es prioritario respecto al conocimiento verbal-conceptual pero que están integrados jerárquicamente y necesitan uno del otro" (Maslow, 1966, cit. por Rowan, 1985, p.87).

Estos tres elementos que aquí se han destacado, entre los que constituyen requisitos de la investigación en el nuevo paradigma, han formado parte de la manera habitual de abordar el trabajo terapéutico e investigador de toda sesión clínica. En ella se considera importante ejercitar un trabajo como coinvestigadores y cosujetos, atender con la máxima receptividad posible con actitud holista y disponer de una vivencia experiencial previa de los trabajos propuestos a la vez que facilitan los propios investigadores-psicoterapeutas cierto grado de actitud experiencial en el transcurso de la sesión.

En el prólogo del libro citado, Rowan y Reason resumen con estas palabras lo esencial del Nuevo Paradigma:

Lo que estamos construyendo en la investigación del nuevo paradigma es un acercamiento a la investigación que es una sistemática y rigurosa búsqueda de verdad, pero que no extermina todo lo que toca; estamos buscando una vía de investigación que pueda libremente ser llamada objetivo-subjetiva. El nuevo paradigma es una síntesis de investigación ingenua e investigación ortodoxa. Una síntesis que es muy opuesta a la antítesis a la que suplanta (Rowan y Reason, 1985, p. XIII).

Respecto a las limitaciones que se pueden dar en la metodología experimental u observacional convencionales, el psicólogo científico Child, catedrático de Yale, no tiene inconveniente de reconocerlo.

Muchos investigadores psicológicos, por otra parte, se abstraen tanto en el perfeccionamiento de sus métodos de investigación que su manera de pensar queda dominada por el método y no por el objeto de la investigación. Cuando el método se convierte en un modo de pensar, los experimentalistas quedan a un paso de caer en una manera de pensar mecanicista y manipulativa. El método experimental se basa en la manipulación de lo que se hace con individuos o animales que sirven de sujetos, y en observar el efecto en su conducta. Los psicólogos que aplican exclusivamente el método experimental, o que lo tienen siempre en mente como ideal, tenderán a creer que los procesos psicológicos son análogos a las relaciones físicas simples que han estudiado en el laboratorio de física [...] Si los mismos psicólogos estuvieran más atentos a entender a sus sujetos, advertirían que el resultado del experimento realizado con seres humanos es, en general, menos preciso que el llevado a cabo en la física (Child, 1975, pp. 23s.). 


\section{Principales errores de algunos psicólogos humanistas}

\section{$1^{\circ}$ Infidelidad a los iniciadores}

Un primer error ha sido el olvido o desconocimiento de convicciones y aspiraciones de los iniciadores del Movimiento de la Psicología Humanista.

Una de las características y logros del Movimiento de la Psicología Humanista fue su desmarque de la lucha de poder - principalmente entre los conductistas y los psicoanalistas ortodoxos- aspirando a imponer su respectivo paradigma en el mundo académico. Los psicólogos creadores de nuevos modelos terapéuticos, o de variados tipos de procedimientos de intervención, difícilmente podían ver acogidas sus demandas para presentar sus experiencias y conclusiones en los Congresos o Jornadas promovidos por los dos colectivos que se encontraban en el poder. Las mismas dificultades se encontraban para publicar artículos en revistas, dando a conocer sus innovaciones. Muchos de los representantes de nuevos modelos terapéuticos estrenaron la experiencia de dar a conocer sus aportaciones, gracias a la actitud acogedora y respetuosa del pluralismo que caracterizó a los congresos nacionales o internacionales de Psicología Humanista que tuvieron lugar en los años setenta y ochenta del siglo pasado. Entre los muchos modelos de psicoterapia -o, simplemente, técnicas terapéuticas-que rechazaban explícita o implícitamente los enfoques atomistas, o reduccionistas, o mecanicistas, o deterministas, y que en algún grado destacaban la eficacia de lo experiencial por encima de lo informativo en la sesión terapéutica, destacaron, además de la Psicoterapia centrada en la persona, de Carl Rogers, y la Psicoterapia Existencial de Rollo May e Irvin Yalom, la Psicoterapia de la Gestalt de Perls -mal llamada la Gestalt-, el Análisis Transaccional de Berne, la Psicosíntesis de Assagioli, el Focusing de Gendlin, y la Bioenergética de Lowen, entre otros muchos. Todos ellos podían considerarse integrados en el Movimiento de la Psicología Humanista y, gracias a la favorable acogida que encontraron en éste, pudieron encontrar ayudas para darse a conocer y difundirse.

Sin embargo, la realidad es que una parte de los psicoterapeutas implicados en estos modelos $-\mathrm{y}$, por ello, supuestamente humanistas- no han sabido actuar con coherencia respecto a las convicciones y aspiraciones de los iniciadores del Movimiento. Además, no pocos de ellos las han desconocido. Han caído en algunas de las actitudes o actuaciones de las que aquellos iniciadores compartieron su rechazo. Por ejemplo: manifiestan algún tipo de interpretación reduccionista, o determinista, o una actitud de escuela como "sistema cerrado", o centramiento excesivo sólo en lo patológico. Por ello no pueden considerarse psicoterapeutas humanistas, utilicen o no este calificativo.

\section{$2^{\circ}$ Despreocupación respecto al diálogo académico}

Otro error que han cometido bastantes psicoterapeutas humanistas consiste en la excesiva despreocupación por la formación teórica, por el diálogo con las 
instituciones académicas, y por la investigación científica, dando con ello pie a la desconfianza por parte de los profesores universitarios

Ha sido, indudablemente, un acierto que en los centros o institutos para la formación en cualesquiera de los diversos modelos de línea humanista-existencial haya prevalecido, en general, el tiempo dedicado a la formación práctica y experiencial; es decir, al hecho de experienciar, por parte de los alumnos, la práctica de variados procedimientos de intervención -fuesen verbales, o con actividad imaginaria, o psicocorporales-, y comprobar sus posibles efectos sobre sí mismos, para su crecimiento personal o, en ocasiones, para la terapia respecto a algún posible síndrome psicopatológico o trastorno de personalidad.

Pero hay que considerar un error que, por el hecho de reconocer la importancia de la parte práctica de la formación, se haya en ocasiones desatendido la formación teórica. Haber reducido la formación a la vivencia de una colección de técnicas terapéuticas, sin haber ofrecido información, por ejemplo, sobre: a) tipos de problemas y de pacientes para los que puedan ser apropiadas; b) fase de la terapia en la que resultan procedentes; c) requisitos para su correcta aplicación, etcétera. Asimismo, información sobre los contenidos teóricos del correspondiente modelo terapéutico respecto a: a) cómo se entiende la meta de la terapia; b) cómo se actúa para lograr una relación terapéutica satisfactoria entre el profesional y el paciente; c) qué principales estrategias se utilizan en ese modelo; d) qué técnicas verbales, o imaginarias, o psicocorporales -incluidas otras procedentes de distintos modelos terapéuticos- podrán armonizarse con los fundamentos teóricos implicados; e) también sería conveniente adquirir un conocimiento suficiente sobre: cómo se entiende en el modelo la personalidad sana, frente a la patológica, lo mismo sobre los procesos sensoriales, emocionales, cognitivos y conductuales (o práxicos). Y todos estos contenidos teóricos, ¿cómo se han justificado? ¿qué experiencias y razones se han ofrecido por parte de los autores del modelo?

Es decir, la formación no consiste sólo en practicar una colección de recetas supuestamente terapéuticas, aceptadas por una actitud de credulidad basada a veces en el poder seductor del formador. El formando habrá logrado un conocimiento inteligente y práctico de ese modelo, de sus fundamentos teóricos, enriquecidos por su experiencia personal.

Este mismo autor, catedrático en Yale, del que ya he mostrado su capacidad de autocrítica respecto a la tradición científica, lamenta, por otra parte, el desinterés de los psicólogos humanistas respecto a lo científico.

Muchos psicólogos humanistas están tan abiertos en pro del modelo humano de hombre que hacen caso omiso del aspecto de la observación sistemática de la ciencia. Al tratar su modelo a la luz de su experiencia cotidiana o de la práctica clínica, pasan por alto que gran parte de los testimonios sistemáticos de la ciencia no desdicen de su materia (Ibidem, p. 23).

Y refiriéndose a Maslow, del que reconoce su preparación y experiencia 
científica y elogia algunas de las técnicas de observación que ideó para medir la sensibilidad personal para los estilos artísticos, sin embargo se lamenta de que dejase sin concluir algunas de sus interesantes investigaciones, o las concluyera con informes finales insuficientemente convincentes, incluido su interesante estudio sobre las personas autorrealizadas.

\section{$3^{\circ}$ Eclecticismo tecnológico indiscriminado}

La integración metodológica, en el propio modelo terapéutico, de procedimientos de intervención procedentes de otros modelos, se ha señalado como uno de los logros que ha podido incrementar el poder terapéutico de las intervenciones. Ahora bien, en no pocas ocasiones esta intervención tecnológica se ha llevado a cabo de forma indiscriminada y precipitada, sin haberse planteado algunas cuestiones previas como las siguientes: ¿Implica esta técnica unos presupuestos teóricos incompatibles con una psicoterapia humanista? ¿Implica, por ejemplo, unos presupuestos reduccionistas, o atomistas, o mecanicistas, o deterministas? En este caso se deberá comprobar si puede resultar factible practicar determinado procedimiento de intervención desprendiéndolo de tales presupuestos teóricos incompatibles. Por ejemplo, si un psicoterapeuta tiene interés en utilizar procedimientos de las denominadas "Constelaciones Familiares" de Bert Hellinger ies consciente del carácter claramente determinista de los presupuestos teóricos de este modelo? ¿se ha planteado si sería factible utilizar sus técnicas desprendidas de esos presupuestos? Prescindir de plantearse estas cuestiones y de comprobar si puede resolverlas constituiría caer en el error de un eclecticismo tecnológico indiscriminado.

Se puede señalar otro ejemplo, respecto a la integración de la Programación Neurolingüística de Bandler y Grinder. Esta metodología ofrece técnicas de indudable poder psicoterapéutico, según han podido comprobar desde hace treinta y cinco años los psicólogos del Instituto Erich Fromm de Psicoterapia Integradora Humanista. Ahora bien, dado el poder que tienen sobre el psiquismo del paciente, pueden ser practicadas de forma muy manipulativa, provocando cambios contrarios a la voluntad del paciente. Hay declaraciones de sus creadores que invitan a este tipo de actuación. Es evidente que ello es incompatible con una psicoterapia humanista. Además el tipo de relación que ejercían los fundadores ya colocaba al paciente en una posición de clara inferioridad, pasividad y dependencia respecto al terapeuta. Estas actitudes son claramente incompatibles para una relación terapéutica de orientación humanista-existencial, en la que el paciente tiende a ser el auténtico protagonista de su experiencia de cambio curativo con la ayuda del experto profesional.

A la hora de integrar métodos o técnicas procedentes de otros modelos constituye un error -relacionado con lo anterior- haber caído a veces en una credulidad precipitada ante toda novedad terapéutica, sobre todo si se está convirtiendo en una moda, gracias a su eficiente marketing. 


\section{$4^{\circ}$ "Emocionismo"}

Otro error nada infrecuente ha sido el paso de la libre y saludable expresión emocional al "emocionismo".

Ya hace veintiocho años, en la Revista de Psiquiatría y Psicología Humanista, fundada en el año 1981, y que desde 1990 pasó a denominarse Revista de Psicoterapia, se publicó un artículo de John Rowan, presidente entonces de la Sociedad inglesa de Psicología Humanista, en el que refiriéndose a errores de los psicólogos humanistas denunció, entre otros, el "emocionismo", y sobre el cual afirmó:

Uno de los mejores modos para entrar en el reino de la subjetividad en el que actúa la terapia es el de entrar profundamente en contacto con las emociones. Desgraciadamente todo esto se puede transformar fácilmente en un culto de las emociones fuertes por sí mismas, como si fuesen un fin antes que un medio. Yo he visto personas tiranizadas e intimidadas porque no expresaban sus emociones, o porque no estaban expresando las emociones correctas (por ejemplo, la rabia). Lo peor es que he visto criticar a las personas porque no expresaban en todo momento sus sentimientos (Rowan, 1986, p. 38).

Un logro de las psicoterapias humanistas -al cual ya me he referido- ha sido indudablemente el haber destacado la importancia de los procesos afectivos en la vida de las personas, entendidos como riquezas del potencial humano, y no sólo como problemas emocionales en el caso de trastornos. Asimismo, haber facilitado una profunda libertad en la expresión emocional verbal y no verbal, en las sesiones terapéuticas individuales o grupales. Pero una cosa es practicar procedimientos de intervención facilitadores de la catarsis por la expresión profunda, por ejemplo, de la rabia, o la tristeza en situación de duelo, etcétera, y otra cosa es convertir la expresión emocional intensa en panacea casi obligada para considerar provechosa una sesión de terapia individual o grupal. Este es un error que han cometido a veces los psicoterapeutas de la Gestalt, o de la Bioenergética, entre otros. En muchos procesos psicoterapéuticos humanistas pueden ser mayoría las sesiones en las que el paciente -ayudado con frecuencia por técnicas con actividad imaginaria o psicocorporales- reviviendo experiencias antiguas, a veces de la infancia, o imaginando situaciones futuras temidas o deseadas, experimente un fluir emocional terapéuticamente liberador. Pero pensar que cuando en una sesión no se ha producido este tipo de vivencia y expresión emocional catártico se haya perdido el tiempo es caer en "emocionismo".

\section{$5^{\circ}$ Potenciar el narcisismo}

Un peligro a tener en cuenta, a la vista de las actuaciones de algunos psicoterapeutas, es el ejercicio de una psicoterapia potenciadora de una actitud narcisista y despreocupada de actitudes solidarias.

Una parte de los creadores de los primeros modelos terapéuticos humanistas 
se destacaron por su especial confianza en la práctica terapéutica grupal. Esta se prestaba a facilitar entre los participantes -aparte de la superación de sus correspondientes problemas psicológicos- el desarrollo de sus potenciales humanos, entre ellos el entrenamiento en la empatía emocional, en la actitud altruista hacia las compañeras y compañeros, en el reconocimiento sereno de las propias limitaciones, etcétera. Es decir, vivencias nada favorecedoras del cultivo de una actitud narcisista. Pero -como ya detectó y criticó Gendlin en 1987-, a veces, el terapeuta humanista -en sesión individual o grupal- ha ofrecido un modelo de persona con exceso de narcisismo, y ha dado pie a una versión distorsionada del concepto de "autorrealización" o "autoactualización", entendido de forma individualista, e inhibidora de actitudes altruistas y solidarias. Con ello no se ha sido fiel a la idea genuina que sobre estos conceptos tuvieron, por ejemplo, Fromm, Horney, Ch. Bühler, Bugental y Maslow. Para evitar esta versión distorsionada resultaría más expresivo referirse a esta meta de la terapia con el término "autorrealización individual y social".

Una psicoterapia que contribuya sólo a que burgueses depresivos, o ansiosos, o dependientes salgan de la terapia contentos y relajados, pero incapaces de ejercer un influjo social bienhechor en sus ámbitos familiar, profesional, social, científico, artístico, etcétera, no se puede considerar una terapia humanista satisfactoria. Si no se contribuye con ella a desarrollar en los pacientes el potencial humano que les capacite para ser ciudadanos que puedan contribuir algo en humanizar la sociedad, algo ha fallado. No resulta coherente, por ejemplo, con estas declaraciones sobre características de la Psicología Humanista, según Maslow y según Bugental, dos de sus fundadores.

La Psicología debería ser más humanística, más interesada por los problemas de la humanidad, y menos por los problemas del gremio (Cit. en Misiak y Sexton, 1973, p. 114).

Entre los diez puntos con los que se definió la Psicología Humanista, en el Congreso Europeo celebrado en Ginebra en 1980, se encontraban estos:

- Anima a la apertura y la honestidad como la mejor conducta para la vida social e igualmente en relación consigo mismo

- Le concierne lo que se relaciona con los nuevos estilos de vida y con la responsabilidad ecológica, unidos a la conservación de la energía y los recursos sociales

- Trata de la teoría y la práctica del funcionamiento de las organizaciones y de su transformación en lugares nutricios donde las personas puedan expandirse

En este sentido no podemos olvidar varios encuentros promovidos por Rogers entre grupos políticos enfrentados, en Irlanda del Norte, o sus aportaciones a la renovación pedagógica. 


\section{$6^{\circ}$ Peligro de potenciar el "autonomismo"}

El desarrollo del potencial humano, o crecimiento personal, entendido como meta en muchas psicoterapias humanistas -que se ofrecen no sólo a personas con trastornos psicológicos, sino también a personas sanas- incluye la capacidad de sentirse responsable de la propia vida y del desarrollo de la propia persona. Este desarrollo no está sólo condicionado por factores genético-biológicos y por influencias socioculturales (incluidas las educacionales), sino que depende de las historia de las decisiones libres de cada uno a lo largo de su vida. La principal obra creadora que está en nuestras manos -a pesar de los condicionamientos mencionados- es la del desarrollo de nuestra personalidad.

Pero el logro de este sentido de responsabilidad personal, vivido de forma desorbitada, puede conducir al olvido de que no somos autosuficientes, que necesitamos de los otros, que somos animales sociales. Esta conciencia de sentirnos autónomos, con palabras de Rowan

puede transformarse en un deseo patológico de ser independiente de cualquier persona existente en el mundo. Una persona así se convierte en alguien bastante incapaz de amar, porque ello implica dependencia de otro, nos guste o no, lo diga o no la teoría (Rowan, 1986, p. 38).

\section{Responsabilidades para el futuro de la Psicología Humanista}

Ante todo, la primera responsabilidad es evitar reincidir en algunos de los errores mencionados y continuar desarrollando los logros ya obtenidos. Además de esto, se pueden proponer las seis responsabilidades siguientes:

\section{$1^{a}$ Implicación en la investigación científica}

Una responsabilidad que la Psicologia Humanista tiene que afrontar es la de fomentar que algunos psicólogos humanistas se impliquen en la investigación científica, aplicando, según el tipo de objeto a investigar, metodologías convencionales, o bien las del nuevo paradigma humanista.

En la mayoría de los casos, la primera investigación científica que puede realizar un psicólogo es la que lleva a cabo en ocasión de elaborar la tesis doctoral. En aquellas universidades -como muchas de las españolas- en las que son rechazadas las propuestas de tesis doctorales de línea existencial humanista, no se puede criticar luego a los psicólogos humanistas de estar desinteresados de la investigación. Los psicólogos humanistas tendrán que espabilarse para poder elaborar esas tesis en alguna de las pocas universidades que las puedan acoger, y también, las que puedan respetar que la investigación no necesariamente se realice con la metodología experimental, sino también con metodologías observacionales, y con las predominantes en el nuevo paradigma. 


\section{$2^{a}$ Integrarse en el mundo académico}

Una tarea pendiente es la de saber inspirar y merecerse la confianza por parte del mundo académico.

La actitud recelosa que se ha mantenido en muchas universidades respecto a las psicoterapias humanistas, y a la Psicología Humanista-Existencial en general es, por una parte, el tributo que casi siempre ha tenido que pagar toda innovación importante. Son abundantes las experiencias sobre este problema a lo largo de la historia. Recordemos el caso de Louis Pasteur, que tuvo que sufrir numerosos insultos y amenazas, antes de que pudiera demostrar a la comunidad científica la validez de sus hipótesis sobre los virus como factores patógenos y sobre las vacunas como recursos curativos. Los médicos de su entorno no eran capaces de aceptar que estos descubrimientos los hubiese hecho un químico.

Ahora bien, parte de la culpa de esta actitud de recelo y rechazo hay que atribuirla a la imprudencia de algunos psicoterapeutas humanistas. En el primer centro importante de psicólogos humanistas de Esalen, en California, participaron personalidades valiosas y creativas implicadas en el Movimiento, pero juntamente con ellos, algunos psicólogos y terapeutas improvisadores y aventureros. En 1964 tuvo lugar la First Old Saybrook Conference, en la que estuvieron presentes buena parte de los que aspiraban a un cambio de rumbo en la psicología, interesados por lo tanto en el Movimiento de la Psicología Humanista. Estaban presentes, entre otros, los principales psicólogos de la personalidad americanos como Allport, Murray, Kelly y Murphy. Pero ya se ha dicho que los tres últimos se desvincularon del Movimiento, al comprobar actuaciones descontroladas de algunos terapeutas. También se desvinculó Rollo May, aunque poco después se reintegró.

Es decir, las críticas a la Psicología Humanista no se han debido sólo a la posición rígida y refractaria a las innovaciones predominantes en el mundo académico. Se han debido también a las imprudencias cometidas al principio por algunos terapeutas humanistas grupales, abusando del poder de algunas técnicas para provocar catarsis emocionales. Buena parte de los prejuicios han desaparecido en muchos lugares. Las excesivas actitudes de estilo adolescente de algunos psicoterapeutas humanistas han pasado a ser más adultas, sin perderse su estilo creativo. Pero queda todavía mucho por hacer. Aquí también hará falta actuar con más inteligencia emocional, para lograr inspirar más confianza respecto al mundo académico.

Teniendo presentes estos antecedentes y circunstancias, los psicoterapeutas humanistas tendrán que relacionarse -en el mundo académico- con suficiente inteligencia emocional, para lograr un mayor crédito en ese ambiente, y conseguir que los inevitables prejuicios y temores ante las innovaciones psicoterapéuticas, vayan disminuyendo. 


\section{$3^{a}$ Fomentar el diálogo con otras corrientes y en su propio seno}

Otra responsabilidad a cargo de la Psicología Humanista es la de favorecer la comunicación con los psicólogos cognitivos, los psicoanalistas, los psiquiatras biologistas, los neurocientíficos, etcétera, para no acabar en una situación de guetto. También convendría recuperar una mayor comunicación entre las diferentes escuelas psicoterapéuticas humanistas, como la que tenía lugar en los congresos de Psicología Humanista de los años setenta y ochenta del pasado siglo.

Una característica de los Congresos de Psicología Humanista, desde los comienzos del Movimiento, fue su gran apertura al pluralismo de modelos psicoterapéuticos y a una gran diversidad de aportaciones innovadoras sobre métodos y procedimientos de intervención. Lo mismo, respecto a aportaciones psicológicas en campos diferentes de la psicoterapia. Probablemente fueron los primeros congresos que podían acoger, por ejemplo, aportaciones de asiáticos o de aborígenes americanos. En uno de los congresos europeos de aquellos años uno de los actos principales corrió a cargo de un pielroja norteamericano, que expresó sus aportaciones desde su paradigma cultural. Era admirable comprobar la ausencia de prejuicios culturales que se respiraba en aquel ambiente.

Sería positivo que esta actividad de respeto al pluralismo y de intercambio respetuoso y enriquecedor de experiencias desde diferentes paradigmas y escuelas psicológicas fuese favorecida y promovida por los psicólogos humanistas en el futuro.

La conclusión de Irvin Child (1975), después de su recorrido por autores en los que se ha dado convergencia de posiciones, fue la siguiente: "La tradición científica en la investigación psicológica y el pensamiento humanístico, cual lo veo, se necesitan mutuamente para su enriquecimiento" (Ibidem, p. 175). Ahora bien, para los temas de investigación más interesantes la tradición científica convencional será insuficiente. Habrá que recurrir al Nuevo Paradigma, ya referido como un logro importante.

\section{$4^{\mathrm{a}}$ Atender a la vivencia sana del proyecto vital}

De cara al futuro, a la Psicología Humanista le cabe la responsabilidad de prestar más atención al problema del "vacío existencial” y del logro de una vivencia sana del proyecto vital, sin confundir los trastornos existenciales y transpersonales con los trastornos depresivos convencionales.

Habría que investigar hasta qué punto todo terapeuta convendría que fuese consciente sobre las principales aspiraciones que forman parte de su proyecto vital. Un proyecto vital renovado periódicamente de forma inteligente y libre, no dependiente de presiones ambientales o de "guiones de la vida" inconscientes (en el sentido de Berne, 1974). Un proyecto de vida favorecedor del crecimiento personal propio, de los otros con los que el terapeuta se relacione, y con influencia humanizadora sobre las instituciones en las que se encuentre implicado.

Muchos de los psicólogos humanista-existenciales será bueno que sigan 
sabiendo diferenciar entre la angustia neurótica y la angustia existencial. Que sigan desaconsejando la toma precipitada de fármacos tranquilizantes, sobre todo respecto a la angustia existencial. Que sean conscientes sobre las implicaciones y consecuencias humanizadoras que puede tener esta segunda. Y que comprueben hasta qué punto la elección inteligente de un sano proyecto vital puede ser un buen recurso preventivo, respecto a los posibles peligros de tal tipo de angustia, y de la vivencia del "vacío existencial".

\section{$5^{\text {a }}$ Humanizar, además de individuos, estructuras sociales}

Si la Psicología Humanista quiere ser fiel a sus raíces, necesita lograr una influencia terapéutica humanizadora, no sólo respecto a las personas individuales, sino también respecto a las estructuras sociales.

Como ya se ha recordado, en el Movimiento de la Psicología Humanista hubo, desde sus inicios, psicólogos y representantes de otras ciencias humanas, notablemente motivados para poder contribuir a una gradual transformación de la sociedad.

Antes de la fundación del Journal of Humanistic Psychology y de la Association for Humanistic Psychology, Maslow, en 1957, había declarado una serie de responsabilidades de la psicología, cara al futuro y, como ya se ha dicho, ésta era la primera de ellas.

Elisabeth Campbell, en un artículo en el Journal of Humanistic Psychology, en 1984, publicaba el resultado de treinta y seis entrevistas en profundidad con líderes de la Psicología Humanista. Respondían a la pregunta siguiente: “¿Qué contribución puede realizar la Psicología Humanista hacia la realización o el incremento de la posibilidad de conseguir una imagen del futuro positiva, autodeterminada y auto-actualizada, en los próximos diez años?". Entre los entrevistados había representantes de enfoques diferentes y campos de aplicación distintos dentro de la Psicología Humanista: educadores, psicoterapeutas, profesores universitarios, terapeutas corporales, directivos de la Association for Humanistic Psychology. Se identificaron siete tendencias del movimiento. La tercera decía:

Habrá un cambio de énfasis, alejándose del interés actual acerca del crecimiento personal hacia la toma de responsabilidades sociales y políticas. Va a incrementarse el interés acerca de la persona en relación con el entorno (Campbell, 1986, p. 26).

No dispone el autor de suficiente información sobre lo que se haya realizado, en este sentido, en diferentes países; pero piensa que es menos de lo esperado. A la vista de los actuales problemas del mundo, merece la pena descubrir nuevas formas de implicarse desde la Psicología Humanista. Ciertamente se puede considerar que una parte importante de las conductas y actitudes practicadas por dirigentes políticos, económicos, jurídicos, etc., de la vida social, que han tenido consecuencias perjudiciales, deshumanizadoras, pueden ser debidas a deficiencias psicológicas -o incluso psicopatologías- de las personas responsables. Pueden depender de falta de sensibilidad, o de sentimientos positivos, o de inteligencia emocional, o de 
distorsiones en los procesos cognitivos, etcétera.

Por lo tanto, si los psicólogos humanistas-existenciales tienen la oportunidad de ayudar a que los ciudadanos responsables y, en especial, los que ocupan lugares de poder político, económico, social, y cultural, desarrollen satisfactoriamente su potencial humano, este hecho ya puede ser una aportación específica de los psicólogos, para la transformación de la sociedad. Porque, como se ha expuesto en otro lugar (Rosal, 2012; 2014), si pensamos en la importante actitud de "solidaridad para la justicia", difícilmente puede cultivarse por personas con bloqueos o distorsiones de los procesos sensoriales, afectivos, cognitivos, y otros. Y sin la vivencia más generalizada de este valor no parece posible que pueda contribuirse a una transformación humanizadora de la sociedad. Pero quizá no sea suficiente esta contribución a partir solamente del crecimiento personal de individuos. Parece que sería conveniente contribuir a la humanización de grupos y estructuras sociales, ya que también en éstas -como señaló Fromm- se dan también patologías.

\section{$6^{\mathrm{a}}$ Concienciar de sus presupuestos antropológicos y epistemológicos}

Una última responsabilidad a tener en cuenta es la de contribuir a que en cada modelo terapéutico se llegue a ser consciente del contenido y fundamentos de los presupuestos antropológicos y epistemológicos implicados (filosóficos y científi$\cos )$.

En la mayoría de las psicoterapias humanistas se encuentra, al menos implícita, la fenomenología filosófica de Husserl, por la primacía que se concede al conocimiento experiencial (Gimeno-Bayón, 2015). Asimismo, se concede más importancia al conocimiento por "comprensión" que por la "explicación” causal, tal como había sostenido el filósofo Dilthey, al tratarse de las ciencias del espíritu (como denominaba a las humanas) a diferencia de las ciencias naturales (Física, Química, Biología, etcétera). Se concede especial interés a la captación del aspecto procesual de la existencia humana, como habían sostenido William James -filósofo antes de fundar uno de los primeros laboratorios para la investigación científica de los procesos psicológicos- y su amigo y filósofo Henri Bergson.

Puede comprobarse también, respecto a lo epistemológico, que en mayoría de los psicólogos humanistas está implícita una teoría sobre el conocimiento humano que no se fundamenta ni en el denominado Realismo filosófico, ni en el Idealismo alemán. Es decir, ni se supone la capacidad de captar la esencia de la realidad exterior o interior como una especie de fotografía mental, ni se supone, por el contrario, la negación de tal realidad exterior o interior, si lo conocido se considera pura creación de la mente racional humana. La teoría implícita predominante en los psicólogos humanistas reconoce la capacidad cognitiva (por razonamiento lógico o por intuición, a partir de la experiencia) de captar la realidad extramental pero siempre condicionada por algún grado de subjetividad, según las características del sujeto cognoscente y sus circunstancias. Esta teoría, en Epistemología filosófica fue denominada Realismo Crítico -o con otros términos- y en Psicología la propuso 
Kelly con el nombre de Constructivismo.

Aparte de estos presupuestos relacionados más bien con la Teoría del Conocimiento, todo psicólogo -sea o no existencial humanista- tiene alguna Antropología filosófica implícita, es decir alguna teoría general sobre la naturaleza humana y sus potenciales esenciales, e igualmente una teoría axiológica, o escala de valores éticos. Parte de la convicción de que la conducta humana no depende exclusivamente de factores genéticos más influencias socio-culturales (incluidas las educacionales), sino que su conducta y el desarrollo de su personalidad y de su crecimiento personal depende principalmente de la historia de sus decisiones libres.

Presupone también disponer de un potencial psicológico denominado normalmente "voluntad", que no se reduce a la fuerza de los impulsos y necesidades de base más o menos fisiológica o cultural. Estos últimos presupuestos filosóficos relacionados con la capacidad de libertad y responsabilidad personal deben mucho a la influencia de algunos filósofos existencialistas.

Una parte importante de los psicólogos humanistas -no sólo los de la denominada Psicología Transpersonal- parten de la convicción filosófica de que la naturaleza humana integra, además de factores biológicos, somáticos, y mentales (los que Watson negó), también dispone de potenciales espirituales o místicos, que la capacitan para captar y vivenciar lo trascendente o transpersonal.

Aparte de esta breve selección de presupuestos epistemológicos, antropológicofilosóficos, y axiológicos presentes en mayoría de modelos terapéuticos humanistas, aparecen otros más peculiares de cada uno de ellos. Parece preferible que estas convicciones inconscientes pasen a ser conscientes. Y mejor - para profundizar más-, si además de percatarse de ellas, puede conocerse cómo fueron fundamentadas por esos filósofos, a partir de la experiencia y la razón discursiva o intuitiva. Y, por lo tanto, cómojustificaron su rechazo-total o parcial-a teorías antropológicas diferentes.

\section{Conclusiones}

Tras este recorrido sobre los principales contenidos teóricos y metodológicos que han estado presentes desde 1961 en el trabajo de los psicoterapeutas humanistas, se han podido destacar, en este trabajo, 14 logros, 6 errores y 6 responsabilidades. Los historiadores de los distintos modelos de psicoterapias humanistas -con variantes en los distintos países donde se han difundido (sobre todo en América, Europa, y Asia), podrán investigar -respecto a cada modelo- en qué grado se han mantenido fieles en lo esencial a las convicciones e iniciadores del Movimiento. Asimismo, en qué grado han enriquecido su metodología terapéutica, y dónde han surgido nuevos modelos terapéuticos que puedan integrarse en este marco de referencia. Ésos son los compromisos que mantiene el equipo de la institución a la que el autor está afiliado. 


\section{Referencias bibliográficas}

Allport, G.W. (1975). La personalidad. Su configuración y desarrollo (5 edición). Barcelona, España: Herder (Traducción del original en inglés de 1963).

Ashen, A. (1968). Basic concepts of eidetic psychotherapy. Nueva York: Brandon House.

Ashen, A. (1972). Eidetic parent test and analysis. Nueva York: Brandon House.

Ashen, A. (1977). Eidetics: An Overview. Journal of Mental Imagery, 1(1), 5-38.

Ashen, A. (1994). Imagery Bibliography. Jornal of Mental Imagery, $18(1 \mathrm{y} 2)$.

Ashen, A. (Ed.) (1994). Imagery, Drama and Transformation. The Journal of Mental Imagery, $18(1 \mathrm{y} 2)$.

Assagioli, R. (1973). Principi e metodi della Psicosintesi terapeutica. Roma: Astrolabio. (Traducción del original en inglés de 1965).

Assagioli, R. (1989). El acto de voluntad. México: Trillas (Traducción del original en inglés de 1973).

Berne, E. (1974). ¿Qué dice usted después de decir hola? Barcelona, España: Grijalbo (Traducción del original en inglés de 1973).

Bertalanffy, L. von (1974). Robots, hombres y mentes. Madrid, España: Guadarrama (Traducción del original en inglés de 1967).

Bertalanffy, L. von (1976). Teoría General de los Sistemas. México: Fondo de Cultura Económica (Traducción del original en inglés de 1968).

Boadella, D. (1985). Entrevista con D. Boadella por Ana Gimeno-Bayón. Revista de Psiquiatría y Psicología Humanista, 11, 67-70.

Bogen, J.E. (1969). The other side of the brain: II. An appositional mind. Bulletin of the Los Angeles Neurological Society, 34, 135-162.

Bugental, J.F.T. (Ed.) (1967). Challenges of Humanistic Psychology. New York: McGraw-Hill.

Campbell, E. (1986). La Psicología Humanista. El fin de la inocencia. Revista de Psiquiatría y Psiología Humanista. 14/15, 19-32 (Traducción del original en inglés de 1984).

Cencillo, L. (1975). Dialéctica del concreto humano. Madrid, España: Marova.

Child, I. (1975). Psicología Humanista y la tradición experimental. México: Limusa (Traducción del original en inglés de 1973).

Crampton, M. (1969). The use of mental imagery in psychosynthesis. Journal of Mental Imagery, 2, 139-153.

Crampton, M. (1974). An historical survey of mental iamgery techniques in psychotherapy and description of the dialogic imagery method. Montreal, Canadá: Canadian Institute of Psychosynthesis.

Crampton, M. (1975). Answers from the unconscious. Synthesis, 2, 140-152.

Crampton, M. (1981). Psychosynthesis. En R.J. Corsini (Ed.), Handbook for innovative psychotherapies (pp. 709723). New York: John Wiley.

Denis, M. (1984). Las imágenes mentales. Madrid: Siglo XXI (Traducción del original en francés de 1979).

Desoille, R. (1938). Exploration de l'affectivité subinconsciente par la méthode du Rêve-Eveillé. Sublimation et acquisitions psychologiques. Paris, Francia: J.L. d'Artrey.

Desoille, R. (1973). Entretiens sur Rêve-Eveillé-Dirigée en Psychotherapie. París, Francia: Payot.

Desoille, R.(1974). Teoria e pratica del sogno da svegli guidato. Roma: Astrolabio (Traducción del original en francés de 1961).

Eysench, H. J. (1952). The scientific study of personality. Nueva York: Macmillan.

Ferrucci, P. (1987). Psicosintesis. Málaga, España: Sirio (Traducción del original en inglés de 1982).

Frankl, V. E. (1980). Ante el vacío existencial. Hacia una humanización de la psicoterapia. Barcelona, España: Herder (Traducción del original en alemán de 1977).

Frankl, V. E. (1988). La voluntad de sentido. Barcelona, España: Herder (Traducción del original en inglés de 1969).

Frankl, V. E. (1990). Logoterapia y Análisis Existencial. Textos de cinco décadas. Barcelona, España: Herder (Traducción del original en alemán de 1987).

Frick, W.B. (1986). Fundamentos conceptuales de la autoactualización. Revista de Psiquiatría y Psicología Humanista, 14/15, 50-73 (Traducción del original en inglés de 1984).

Fromm, E. (1966). El corazón del hombre. México: Fondo de Cultura Económica (Traducción del original en inglés de 1966).

Gazzaniga, M.D. (1970). The bisected brain. New York: Appleton-Century-Crofts.

Gazzaniga, M.S. y Ledoux, J.E. (1978). The integrated mind. New York: Plenum.

Gimeno-Bayón, A. (2012a). Comprendiendo la Psicoterapia de la Gestalt. Lleida: Milenio. 
Gimeno-Bayón, A. (2012b). Análisis Transaccional para terapeutas. Vol.I. Conceptos fundamentales para el diagnóstico y la psicoterapia. Lleida, España: Milenio.

Gimeno-Bayón, A. (2013). Un modelo de integración de la dimensión corporal en psicoterapia. Lleida, España: Milenio.

Gimeno-Bayón, A. (2015, noviembre). Experiencia y existencia en las psicoterapias humanistas. Ponencia pronunciada en el I Congreso Internacional de Psicología y Psicoterapias Humanistas celebrado en Barcelona, España.

Gimeno-Bayón, A. y Rosal, R. (2001) Psicoterapia Integradora Humanista. Manual para el tratamiento de 33 problemas psicosensoriales, cognitivos y emocionales. Bilbao, España: Desclée de Brouwer.

Gimeno-Bayón, A. (2012). Análisis transaccional para terapeutas. Vol. II. Tratamiento de los trastornos de la personalidad y algunos sindromes. Barcelon, España a: Milenio.

Gimeno-Bayón, A. (2016). Psicoterapia Integradora Humanista. Volumen II. Manual para el tratamiento de 69 problemas que aparecen en distintos trastornos de la personalidad (2 $2^{\mathrm{a}}$ ed.). Bilbao, España: Desclée de Brouwer.

Greenberg, L.S. y Korman, L. (1993). La integración de la emoción en psicoterapia. Revista de Psicoterapia, 4(16), 5-19. http://revistadepsicoterapia.com/la-integracion-de-la-emocion-en-psicoterapia.html

Greenberg, L.S., Rice, L.N. y Elliot, R. (1996). Facilitando el cambio emocional. El proceso terapéutico punto a punto. Barcelona, España: Paidós (Traducción del original en inglés de1993).

Heron, J. (1985a). Experiential research methodology. En P. Reason y J. Rowan (Eds.) Human inquiry. A source book of new paradigm research (pp. 153-166). New York: John Wiley.

Heron, J. (1985b). Philosophical basis for a new paradigm. En P. Reason y J. Rowan(Eds.) Human inquiry. A source book of new paradigm research. (pp. 19-36). New York: John Wiley.

Holt, R.R. (1964). Imagery: The Return of the Ostracised. American Psychologist, 19, 254-264.

Holt, R.R. (1972). On the nature and generality of mental imagery. En P.W. Sheehan (Ed.), The function and nature of imagery (pp.6-35). New York: Academic Press.

James, W. (1890-1989). Principios de Psicología. México: Fondo de Cultura Económica.

Karpman, S. (1968). Fairy Tales and Script Drama Analysis. Transactional Analysis Bulletin (7), 26, 39-43.

Kimura, D. (1973). The asymmetry of the human brain. Scientific American, 228, 70-78.

Krech, D. Crutchfield, R.S. y Livson, N. (1973). Elementos de Psicología. Madrid: Gredos (Traducción del original en inglés de 1969).

Lafferty, P., Beutler, L.E. y Crago, M. (1990). Diferencias entre terapeutas más y menos eficaces: un estudio de variables del terapeuta. Revista de Psicoterapia, 1(4), 33-43 (Traducción del original en inglés de 1989). http://revistadepsicoterapia.com/diferencias-entre-psicoterapeutas-mas-y-menos-eficaces-un-estudio-devariables-del-terapeuta.html

Lersch, P. (1971). La estructura de la personalidad ( $8^{\mathrm{a}}$ ed.). Barcelona: Scientia (Traducción del original en alemán de 1966).

Leuner, H. (1969). Guided affective imagery: a method of intensive psychotherapy. American Journal of Psychotherapy, 23, 4-22.

Leuner, H. (1977). The role of imagery in psychotherapy. En S. Arieti y G. Chrzanowski (eds.) New dimensión in psychiatry: A world view. Nueva York: John Wiley.

Leuner, H. (1978). Basic principles and therapeutic efficacy of guided affective imagery (GAI). En J.L. Singer y K.S. Pope (Eds.) The power of human imagination (pp. 125-166). Nueva York: Plenum Press.

Lewin, K., Lippitt, R. y White, R. K. (1939). Patterns of aggressive behavior in experimentally created "social climates". The Journal of social psychology, 10(2), 269-299.

Ley, R.G. (1983). Cerebral laterality and imagery. En A.A. Sheikh (Ed.), Imagery: Current Theory, research and applications (pp. 252-287). New York: John Wiley.

Ley, R.G. (1984). Right hemispheric processing of emotional and imageable words. En En A. Sheikh (Ed.), International Review of mental imagery, 1. Nueva York: Human Sciences Press.

Ley, R.G. y Briden, M.P. (1979). Hemispheric differences in recognizing faces and emotions. Brain and Language, $1,127-138$.

Maslow, A. (1966). The psychology of science. A reconnaissance. Nueva York: Harper and Row.

Maslow, A. (1975). Motivación y Personalidad. Barcelona, España: Sagitario (Traducción del original en inglés de 1954).

Maslow, A. (1982). Una teoría de la metamotivación: las raíces biológicas de la vida valorativa. En R. Walsh y F. Vaughan (Eds.) Más allá del ego. Textos de Psicología Transpersonal, (pp. 182-196). Barcelona, España: Kairos (Traducido del original en inglés de 1980). 
Maslow, A. (1983a). El hombre autorrealizado. Barcelona, España: Kairós (Traducción del original en inglés de 1968).

Maslow, A. (1983b). La personalidad creadora. Barcelona, España: Kairos (Traducción del original en inglés de 1971).

Maslow, A. (1985). The psychology of science. En P. Reason y J. Rowan (Eds.) Human Inquiry. A sourcebook of New Paradigm research (pp.87-92). New York: John Wiley.

May, R. (1974). El hombre en busca de sí mismo. Buenos Aires, Argentina: Editorial Central (Traducción del original en inglés de 1953).

May, R. (1978). El dilema existencial del hombre moderno ( $3^{\mathrm{a}}$ ed). Buenos Aires, Argentina: Paidós (Traducción del original en inglés de 1967).

May, R. (1985). Amor y Voluntad. Las fuerzas que dan sentido a la vida. Barcelona, España: Gedisa (Traducción del original en inglés de 1969).

May, R. (1986). El movimiento de la Psicología Humanista. Revista de Psiquiatría y Psicología Humanista, 1415, 33-35 (Traducción de la Conferencia inaugural del V Congreso Europeo de Psicología Humanista, celebrado en Roma en 1981).

May, R. (1988). Libertad y destino en psicoterapia. Bilbao, España: Desclée de Brouwer (Traducción del original en inglés de 1981).

May, R., Allport, G. W, Feifel, H., Maslow, A. y Rogers, C. (1963). Psicología existencial. Buenos Aires, Argentina: Paidós (Traducción del original en inglés de 1961).

Misiak, H. y Sexton, V.S. (1973). Phenomenological, existential and humanistic psychologies. Nueva York: Grune Stratton.

Murray, H.A. (1962). The personality and career of Satan. Journal of Social Issues, 18, 36-54.

Pinillos, J. L. (1975). Principios de Psicología. Madrid, España: Alianza Editorial.

Pinillos, J. L. (1987). La personalidad. Revista de Psiquiatría y Psicología Humanista, 19/20, 4-17.

Rank, O. (1976). Volonté et psychothérapie. Paris: Payot. (Traducción del original en inglés de 1976).

Reason, P. y Rowan, J. (1985). Issues of validity in new paradigm research. En P. Reason y J. Rowan (Eds.) Human inquiry. A sourcebook of New Paradigm research (pp. 239-252). New York: John Wiley.

Reason, P. y Rowan, J. (Eds.) (1985). Human inquiry. A sourcebook of New Paradigm research. New York: John Wiley.

Richardson, A. (1980). Mental imagery and human memory. Nueva York: St. Martin's Press.

Rosal, R. (1986). Las actitudes del terapeuta humanista. Revista de Psiquiatría y Psicología Humanista 14/15, pp. 64-75. http://revistadepsicoterapia.com/rp101-02.html

Rosal, R. (2012). Valores éticos o fuerzas que dan sentido a la vida. Lleida, España: Milenio.

Rosal, R. (2013). El poder psicoterapéutico de la actividad imaginaria. Lleida, España: Milenio.

Rosal, R. (2014, abril). Procesos sensoriales y emocionales implicados en la actitud solidaria. Ponencia pronunciada en las III Jornadas de la Asociación de Psicoterapia Integradora Humanista, celebrada en Barcelona, España.

Rosal, R. (2015). Revalorización de los potenciales del hemisferio cerebral derecho. Las imágenes en psicoterapia. Revista de Psicoterapia, 26(11), 39-71.

Rowan, J. (1985). A dialectic paradigm for research. En P. Reason y J. Rowan (Eds.) Human inquiry. A sourcebook of New Paradigm research (pp. 93-112) New York: John Wiley.

Rowan, J. (1986). A la caza de la herejía. Revista de Psiquiatría y Psicoterapia Humanista, 14-15, 36-40.

Rychlack (1988). Personalidad y Psicoterapia. Una aproximación a la construcción teórica. México: Trillas (Traducción del original en inglés de 1973).

Sheik, A.A. y Panagiotou, N.C. (1975). Use of mental imagery in psychotherapy: a critical review. Perceptual and motor skills, 41, 555-585.

Shorr, J. E. (1972). Psycho-Imagination Therapy: The integration of phenomenology and imagination. New York: Intercontinental Medical Book.

Shorr, J. E. (1974a). Shorr imagery test. Los Angeles: Institute for Psychoimagination therapy.

Shorr, J. E. (1974b). Psychotherapy through imagery. New York: Intercontinental Medical Book.

Sperry, R.W. y Gazzaniga, M.S. (1967). Language following surgical disconnection of the hemispheres. En F.L. Darley (Ed.), Brain Mechanism Underlying Speech and Language (pp.108-121). New York: Grune and Stratton.

Torbert, W.R.(1985). Why Educational Research Has Been So Uneducational: The Case for a New Model of Social Science Based on Collaborative Inquiry. En P. Reason y J. Rowan (Eds.) Human Inquiry. A sourcebook of New Paradigm research (141-151). Nueva York: John Wiley. 
Vinacke, W.E. (1972). Psicología General. Tomos Iy II. Madrid: Magisterio Español. (Traducción del original en inglés de 1968).

Watson, J.B. (1913). Psychology as the behaviorist views it. Psychological Review, 20, 158-177.

Weiskorpf-Joelson, E. (1968). Meaning as integrating factor. En C. Bühler y F. Massarik (Eds.) The course of human life (pp. 359-383). Nueva York: Springer-Verlag.

Wertheimer, R.W. (1968). Productive thinking. Londres: Tavistock Publications, Social Science, Paper Books (Traducción del original en inglés de 1945).

Zubiri, X. (1992). Sobre el sentimiento y la voluntad. Madrid, España: Alianza y Fundación X. Zubiri. 